OPEN ACCESS

Edited by:

Henry J. McSorley,

University of Edinburgh,

United Kingdom

Reviewed by:

Arvind Sahu,

National Centre for Cell Science, India

Mônica Larucci Vieira,

Institute of Biological Sciences of

Federal University of Minas Gerais

(ICB-UFMG), Brazil

*Correspondence:

Peter F. Zipfe

peter.zipfe/@/eibniz-hki.de

Specialty section

This article was submitted to Microbial Immunology,

a section of the journal

Frontiers in Immunology

Received: 11 June 2019 Accepted: 17 October 2019 Published: 22 November 2019

Citation:

Dasari P, Koleci N, Shopova IA

Wartenberg $D$, Beyersdorf $N$,

Dietrich S, Sahagún-Ruiz A, Figge MT, Skerka C, Brakhage AA and Zipfel PF

(2019) Enolase From Aspergillus

fumigatus Is a Moonlighting Protein

That Binds the Human Plasma

Complement Proteins Factor $\mathrm{H}$,

FHL-1, C4BP, and Plasminogen.

Front. Immunol. 10:2573.

doi: 10.3389/fimmu.2019.02573

\section{Enolase From Aspergillus fumigatus Is a Moonlighting Protein That Binds the Human Plasma Complement Proteins Factor H, FHL-1, C4BP, and Plasminogen}

\author{
Prasad Dasari ${ }^{1}$, Naile Koleci ${ }^{1}$, lordana A. Shopova ${ }^{2}$, Dirk Wartenberg ${ }^{2}$, \\ Niklas Beyersdorf ${ }^{3}$, Stefanie Dietrich ${ }^{4}$, Alfredo Sahagún-Ruiz ${ }^{5}$, Marc Thilo Figge ${ }^{4,6}$, \\ Christine Skerka ${ }^{1}$, Axel A. Brakhage ${ }^{2,6}$ and Peter F. Zipfel ${ }^{1,6 *}$
}

\footnotetext{
' Department of Infection Biology, Leibniz Institute for Natural Product Research and Infection Biology, Hans Knöll Institute, Jena, Germany, ${ }^{2}$ Department of Molecular and Applied Microbiology, Leibniz Institute for Natural Product Research and Infection Biology, Hans Knöll Institute, Jena, Germany, ${ }^{3}$ Institute for Virology and Immunobiology, University of Würzburg, Würzburg, Germany, ${ }^{4}$ Research Group Applied Systems Biology, Leibniz Institute for Natural Product Research and Infection Biology, Hans Knöll Institute, Jena, Germany, ${ }^{5}$ Laboratorio de Inmunología Molecular, Departamento de Microbiología e Inmunología, Facultad de Medicina Veterinaria y Zootecnia, Universidad Nacional Autónoma de México, Mexico City, Mexico, ${ }^{6}$ Institute of Microbiology, Friedrich Schiller University, Jena, Germany
}

The opportunistic fungal pathogen Aspergillus fumigatus can cause severe infections, particularly in immunocompromised individuals. Upon infection, A. fumigatus faces the powerful and directly acting immune defense of the human host. The mechanisms on how $A$. fumigatus evades innate immune attack and complement are still poorly understood. Here, we identify A. fumigatus enolase, AfEno1, which was also characterized as fungal allergen, as a surface ligand for human plasma complement regulators. AfEno1 binds factor $\mathrm{H}$, factor- $\mathrm{H}$-like protein 1 (FHL-1), C4b binding protein (C4BP), and plasminogen. Factor $\mathrm{H}$ attaches to AfEno1 via two regions, via short conserved repeats (SCRs) 6-7 and 19-20, and FHL-1 contacts AfEno1 via SCRs 6-7. Both regulators when bound to AfEno1 retain cofactor activity and assist in C3b inactivation. Similarly, the classical pathway regulator C4BP binds to AfEno1 and bound to AfEno1; C4BP assists in C4b inactivation. Plasminogen which binds to AfEno1 via lysine residues is accessible for the tissue-type plasminogen activator (tPA), and active plasmin cleaves the chromogenic substrate S2251, degrades fibrinogen, and inactivates C3 and C3b. Plasmin attached to swollen A. fumigatus conidia damages human A549 lung epithelial cells, reduces the cellular metabolic activity, and induces cell retraction, which results in exposure of the extracellular matrix. Thus, A. fumigatus AfEno1 is a moonlighting protein and virulence factor which recruits several human regulators. The attached human regulators allow the fungal pathogen to control complement at the level of $\mathrm{C} 3$ and to damage endothelial cell layers and tissue components.

Keywords: complement factor $\mathrm{H}$, moonlighting, immune evasion, plasminogen, blocking phagocytosis 


\section{INTRODUCTION}

The opportunistic pathogenic and saprophytic filamentous fungus Aspergillus fumigatus can cause invasive aspergillosis, a life-threatening disease which affects mainly immunosuppressed individuals and has a high mortality rate $(1,2)$. In patients with impaired lung function such as cystic fibrosis and ectopic asthma, A. fumigatus can also cause airway diseases like allergic asthma (AA) and allergic bronchopulmonary aspergillosis (3-5). Over the past two decades, the increase in A. fumigatus infections has raised the awareness for a better understanding of the interplay between Aspergillus and the human host. To this end, it is relevant to understand how the fungus is recognized by the intact immune system and for compromised individuals whose defective immune response results in clinical manifestations (6). Elucidating the immune escape strategies of A. fumigatus will allow development of new antifungal therapeutics. Inhaled conidia when reaching bronchi are immediately confronted by the host's innate immune system, including complement. Multiple soluble complement proteins and pattern recognition proteins are identified by the proteome approach in human bronchoalveolar lavage and airway fluids $(7,8)$.

Complement as a central part of the innate immune defense orchestrates both the humoral and cellular responses of the human host. This immediately acting cascade is activated by three pathways, the alternative pathway (AP), the classical pathway (CP), and the lectin pathway (CP) (9-11). The human host uses soluble and membrane-bound regulators to protect selfcells and surfaces from toxic complement activation products and to inhibit lysis of bystander cells $(9,10)$. Self-protective fluidphase regulators factor $\mathrm{H}$ and factor- $\mathrm{H}$-like protein 1 (FHL-1) inhibit the AP-mediated damage. Factor $\mathrm{H}$ is a $150-\mathrm{kDa}$ plasma protein composed of 20 short conserved repeats (SCRs) (9). FHL1 , which is derived from the same gene and is encoded by an alternatively spliced transcript, shares SCRs $1-7$ with factor $\mathrm{H}$ and has a C-terminal unique four-amino-acid extension. Both factor $\mathrm{H}$ and FHL-1 act as cofactors for factor I and assist in C3b inactivation, thereby accelerating the decay of the AP C3 convertase. $\mathrm{C} 4 \mathrm{~b}$ binding protein (C4BP) blocks both the $\mathrm{CP}$ and LP (9). C4BP, a $570-\mathrm{kDa}$ plasma regulator, is composed of seven identical $\alpha$-chains and one $\beta$-chain (12). The $\alpha$-chain comprises eight SCRs, and the $\beta$-chain encompasses three SCRs. C4BP acts as a cofactor for factor I, which cleaves $\mathrm{C} 4 \mathrm{~b}$ and accelerates the decay of the CP/LP C3 convertases (13). C4BP acts as a cofactor for factor I-mediated inactivation of C3b in fluid phase $(12,14)$.

Plasminogen, a $92-\mathrm{kDa}$ plasma glycoprotein, is a selfprotective complement regulator. Plasminogen consists of five consecutive disulfide-bonded kringle domains which are linked to a serine protease domain (15). The $\mathrm{N}$-terminal kringle domains mediate cell surface attachment, and often, lysine residues are relevant for the contact (16). Plasminogen is activated by physiological activators, i.e., tissue-type plasminogen

Abbreviations: FHL-1, factor H-like protein 1; ELISA, enzyme-linked immunosorbent assay; DPBS, Dulbecco's phosphate-buffered saline; RT, room temperature; SCRs, short consensus repeats; tPA, tissue-type plasminogen activator; $\varepsilon$-ACA, $\varepsilon$-aminocaproic acid. activator (tPA) and urokinase-type plasminogen activator (uPA) to the protease plasmin (15). Active plasmin dissolves fibrin clots and degrades extracellular matrix components and membrane proteins (17). Plasmin also degrades complement proteins (15, $18,19)$.

A. fumigatus conidia and hyphae activate all three pathways of the complement system $(20,21)$. Resting conidia preferentially activate the AP, whereas swollen conidia and hyphae activate the CP and the LP (22).

Similar to other fungal, bacterial, and multicellular microbial pathogens, A. fumigatus uses multiple strategies to control and to counteract host complement attack. A. fumigatus conidia and hyphae recruit the human plasma regulators factor H, FHL-1, $\mathrm{C} 4 \mathrm{BP}$, and plasminogen and the pattern recognition proteins pentraxin-3 and ficolin-2 (23-26). This pathogenic fungus also inactivates $\mathrm{C} 3$ directly. A. fumigatus-secreted alkaline protease 1 (Alp1) degrades the central human complement proteins $\mathrm{C} 3, \mathrm{C} 4$, and C5 (27). The metalloprotease Mep1 cleaves C3, C4, and C5 and inhibits all three complement pathways (28). Furthermore, the hydrophobic fungal pigment 1,8-dihydroxynaphthalene (DHN) melanin prevents C3b binding to the surface of $A$. fumigatus, thereby allowing escape from host complement attack (22). A role of complement upon A. fumigatus infection is concluded as C5 knockout mice show higher mortality when challenged with A. fumigatus $(29,30)$. Polymorphisms of the human (pentraxin 3 [PTX-3]) MBL (Manan binding lectin 2) or ficolin-2 genes increase susceptibility for A. fumigatus infection $(25,31,32)$.

At present, 23 allergens have been identified from $A$. fumigatus (33). The allergen Aspf2, which is the ortholog of the central Candida albicans immune evasion protein Pral ( $\mathrm{pH}$-regulated antigen 1), is exposed on the surface of resting and swollen conidia and recruits the human plasma regulators factor $\mathrm{H}, \mathrm{FHL}-$ 1 , and plasminogen $(34,35)$. The attached host regulators inhibit opsonophagocytosis and killing of conidia by human neutrophils. Aspf22, also known as enolase (AfEno1), is another A. fumigatus allergen, which has immune evasion potential. AfEnol-reacting immunoglobulins $\mathrm{E}$ (IgE) are present sera from patients with allergic bronchopulmonary aspergillosis $(\mathrm{ABPA})(33,36)$.

Enolase is a well-known microbial immune evasion and moonlighting protein. Enolase from various pathogens, i.e., the fungi A. fumigatus and C. albicans; from Gram-positive bacteria Streptococcus pneumoniae; from Gram-negative bacteria Borrelia burgdorferi; and from the parasite Plasmodium falciparum binds plasminogen [(37-42), Gow]. Enolase from Leptospira interrogans binds factor $\mathrm{H}$ and $\mathrm{C} 4 \mathrm{BP}$, whereas $S$. pneumoniae enolase binds $\mathrm{C} 4 \mathrm{BP}$, but apparently not factor $\mathrm{H}(3,43)$. In the cytoplasm, enolase catalyzes the conversion of 2-phosphoglycerate to phosphoenolpyruvate; at the microbial surface, enolase binds human plasma proteins including plasminogen.

Given the important role of microbial enolases in immune evasion and given the role of AfEno1 (Aspf22) as allergen, we were interested to evaluate the immune evasion features of AfEnol in more detail. Therefore, we asked if and how AfEnol contributes to A. fumigatus immune evasion. To evaluate the binding potential, A. fumigatus AfEno1 was cloned, expressed, 
and purified as a recombinant protein. Recombinant AfEnol bound plasminogen as well as factor $\mathrm{H}$, FHL-1, and C4BP. AfEnol expressed at the fungal surface contributes to immune evasion and assists in virulence. The human proteins attached to AfEnol retain regulatory activity and inactivate complement at the levels of $\mathrm{C} 3$ and $\mathrm{C} 3 \mathrm{~b}$. In addition, plasmin attached to swollen conidia damages human epithelial cells and induces cell retraction.

\section{MATERIALS AND METHODS}

\section{Cultivation of $A$. fumigatus and of Lung Epithelial Cells}

A. fumigatus (ATCCY6645) strains were grown on Aspergillus minimal media (AMM) for 5 days at $37^{\circ} \mathrm{C}$ in the dark, as reported (44). Swollen conidia and hyphae were generated by incubating resting conidia in RPMI containing $10 \%$ fetal calf serum (FCS) for 4 and $8 \mathrm{~h}$, respectively, at $37^{\circ} \mathrm{C}$.

Human lung epithelial cells A549 (ACC 107) were cultivated in DMEM supplemented with FCS $(10 \% \mathrm{v} / \mathrm{v})$ at $37^{\circ} \mathrm{C}$ in a humidified $5 \% \mathrm{CO}_{2}$ incubator and passaged two times per week when the cells reached confluency.

\section{Proteins/Antibodies}

Normal human serum (NHS) was obtained from healthy donors, pooled, and stored at $-80^{\circ} \mathrm{C}$ until use. NHS collection was approved by the ethical committee of the Medical Faculty of the Friedrich Schiller University, Jena, Germany. Purified human factor $\mathrm{H}$, factor I, C4BP, $\mathrm{C} 3 \mathrm{~b}, \mathrm{C} 4 \mathrm{~b}$, and $\mathrm{C} 4 \mathrm{BP}$ were purchased from CompTech (Complement Technology Inc., Tyler, Texas, USA). Factor H/FHL-1 deletion mutants factor $\mathrm{H}_{1-5}$, factor $\mathrm{H}_{1-6}$, factor $\mathrm{H}_{1-7 \mathrm{SFLT}}$, factor $\mathrm{H}_{8-11}$, factor $\mathrm{H}_{11-15}$, factor $\mathrm{H}_{15-18}$, and factor $\mathrm{H}_{19-20}$ were recombinantly expressed as described $(35,45)$. Plasminogen and tPA were purchased from Technoclone GmbH (Vienna, Austria). Fibrinogen and thrombin were obtained from Calbiochem. C4BP and goat human $\mathrm{C} 3$ antiserum and goat human factor $\mathrm{H}$ antiserum, goat human $\mathrm{C} 4 \mathrm{BP}$ antiserum, and goat human $\mathrm{C} 4$ antiserum were purchased from CompTech (Complement Technology Inc., Tyler, Texas, USA). Goat human plasminogen antiserum was acquired from Acris antibodies (Acris Antibodies $\mathrm{GmbH}$, Herford, Germany), and rabbit human fibrinogen antiserum was purchased from Calbiochem (La Jolla, USA). Horseradish peroxidase (HRP)-conjugated goat antirabbit and rabbit antigoat were from Dako (Deutschland $\mathrm{GmbH}$, Hamburg, Germany). Alexa Fluor ${ }^{\circledR}$-647-conjugated donkey antirabbit and Alexa Fluor ${ }^{\circledR}-488$ donkey antigoat were procured from Life Technologies (Darmstadt, Germany). AfEnol antiserum was produced by immunizing rabbits with purified recombinant AfEnol by standard procedures (46).

\section{Cloning, Expression, and Purification of AfEno1}

The gene of A. fumigatus AfEnol with six His residues added at the $\mathrm{N}$-terminus was cloned into the expression vector pET $4.1 \mathrm{a}$ and expressed in Escherichia coli BL21
(DE3) (47). AfEno1 expression was induced with isopropyl$\beta$-D-thiogalactopyranoside (IPTG). Bacteria were collected by centrifugation and lysed by sonication. Thereafter, the bacteria were suspended in lysis buffer containing $20 \mathrm{mM}$ Tris- $\mathrm{HCl} \mathrm{pH}$ $=8,150 \mathrm{mM} \mathrm{NaCl}$, and $10 \%$ glycerol. The lysed cells were centrifuged, and His-tagged AfEnol was purified using Ni-NTA resin (HisTrap 5-ml columns, GE). Recombinant AfEno1 was purified from bacterial lysate, and the protein was not detected in inclusion bodies. Purity of AfEnol was determined after separation in 10\% SDS-PAGE followed by silver staining or western blotting (described below). The protein concentration was determined by Bradford assay (Bio-Rad GmbH Munchen).

\section{Binding Assays}

Factor H, FHL-1, factor H/FHL-1 deletion mutants, C4BP, plasminogen, or gelatin [1 $\mu \mathrm{g} /$ well in $100 \mu \mathrm{l}$ of Dulbecco's phosphate-buffered saline (DPBS)] was immobilized onto a 96well microtiter plate at $4^{\circ} \mathrm{C}$ overnight. After blocking with $0.2 \%(\mathrm{w} / \mathrm{v})$ gelatin in DPBS, AfEnol at increasing amounts was added, and the mixtures were incubated for $1 \mathrm{~h}$ at room temperature (RT). Following washing, the wells were incubated with rabbit AfEnol antiserum in DPBS with 3\% bovine serum albumin (BSA), followed by HRP-conjugated secondary IgGs. After washing, 3,3',5,5'-tetramethylbenzidine (TMB) (Thermo Fisher) was added, and the reaction was stopped with $\mathrm{H}_{2} \mathrm{SO}_{4}$. Absorbance was read at $450 \mathrm{~nm}$ with SpektraMax 190 (Molecular Devices).

In reverse orientation, AfEnol or gelatin $(1 \mu \mathrm{g} /$ well in $100 \mu \mathrm{l}$ of DPBS) was immobilized in microtiter plates. After blocking with $0.2 \%(\mathrm{w} / \mathrm{v})$ gelatin in DPBS, the wells were incubated with factor H, FHL-1, C4BP, plasminogen, or with NHS for $1 \mathrm{~h}$ at $\mathrm{RT}$. The wells were washed and bound regulators were identified as above by specific antisera against the corresponding proteins, followed by HRP-conjugated IgGs.

\section{Biolayer Interferometry}

The binding affinity of AfEnol and factor $\mathrm{H}, \mathrm{C} 4 \mathrm{BP}$, or plasminogen were determined by biolayer interferometry (Forte Bio, Menlo Park, CA) as previously described (19, 34). For each concentration, Ni-NTA biosensors were hydrated in DPBS $(0.001 \%$ gelatin) for $10 \mathrm{~min}$; then recombinant AfEnol was bound to biosensors for $120 \mathrm{~s}$. After washing the sensor (30 s) with DPBS (0.001\% gelatin), factor $\mathrm{H}, \mathrm{C} 4 \mathrm{BP}$, or plasminogen at various concentrations were added as analytes. For each concentration, the association of the complexes was followed for $250 \mathrm{~s}$. After washing the sensor, the dissociation of the complexes was followed for another $250 \mathrm{~s}$. All interactions were performed at RT. As a non-binding control, heat inactivated regulators were used. The data were obtained after subtracting the buffer blank using a 1:1 model of interaction. Graphs were plotted in Graph Pad Prism 5.

\section{Cofactor Assay}

Cofactor activity of factor H or FHL-1 bound to AfEnol was evaluated as described (34). AfEnol or gelatin (1 $\mu \mathrm{g} /$ well in $100 \mu \mathrm{l}$ of DPBS) was immobilized on a microtiter plate at $4^{\circ} \mathrm{C}$, overnight. After blocking the wells with $0.2 \%(\mathrm{w} / \mathrm{v})$ gelatin, factor 
$\mathrm{H}(5,10$, and $20 \mu \mathrm{g} / \mathrm{ml})$, or FHL-1 $(2.5,5$, and $10 \mu \mathrm{g} / \mathrm{ml})$ were added in DPBS, and the mixture was incubated for $1 \mathrm{~h}$ at RT. Following washing, C3b (1 $\mu \mathrm{g} /$ well $)$ and factor I $(1 \mu \mathrm{g} / \mathrm{ml})$ in DPBS were added, and the mixture was incubated for $2 \mathrm{~h}$ at $37^{\circ} \mathrm{C}$. To assess C4BP cofactor activity, C4BP (at 5, 10, and, $20 \mu \mathrm{g} / \mathrm{ml}$ ) was added to immobilized AfEnol or gelatin. Following washing, C4b $(1 \mu \mathrm{g} /$ well $)$ and factor I $(1 \mu \mathrm{g} / \mathrm{ml})$ in DPBS were added; the mixture was incubated for $4 \mathrm{~h} 37^{\circ} \mathrm{C}$. Then reaction was stopped by addition of $\operatorname{Roti}^{\circledR}$-Load 1 and proteins were subjected to SDS-PAGE. Separated proteins were transferred to a membrane. $\mathrm{C} 3 \mathrm{~b}$ and $\mathrm{C} 4 \mathrm{~b}$ cleavage products were identified by Western blotting using goat human C3 antiserum or goat human C4 antiserum, respectively, followed by HRP-conjugated rabbit antigoat antibodies.

\section{Influence of $\varepsilon$-Aminocaprioc Acid ( $\varepsilon$-ACA) and Lysine Residues on AfEno1 Binding to Plasminogen}

$\varepsilon$-ACA at increasing concentrations $(0.625,1.25,2.5,5$, and $10 \mathrm{mM}$ ) and amino acids lysine, arginine, and glutamic acid at the indicated concentrations $(0.375,0.75,1.5,3,6$, and $12 \mathrm{mM})$ were added to plasminogen $(10 \mu \mathrm{g} / \mathrm{ml})$. After incubation ( $1 \mathrm{~h}$ at RT), the complexes were added to immobilized AfEno1. After further $1 \mathrm{~h}$ incubation at RT, bound plasminogen was identified with goat human plasminogen antiserum.

\section{Cleavage of the Chromogenic Substrate S2251}

Plasminogen or plasminogen pre-incubated with $\varepsilon$-ACA $(5 \mathrm{mM})$ or lysine $(10 \mathrm{mM})$ was added to immobilized AfEno1. After $1 \mathrm{~h}$ incubation at RT and washing, the chromogenic substrate S2251 $(30 \mu \mathrm{g} / \mathrm{ml})$ and tPA $(1 \mu \mathrm{g} / \mathrm{ml})$ were added. Then the reaction was incubated at $37^{\circ} \mathrm{C}$, and absorbance was measured every $30 \mathrm{~min}$ at $405 \mathrm{~nm}$ for $24 \mathrm{~h}$ (SpektraMax 190; Molecular Devices). In some wells also the serine protease inhibitor aprotinin $(100 \mu \mathrm{g} / \mathrm{ml})$ was added.

\section{Degradation of Fibrinogen by Plasmin Bound to AfEno1}

AfEno1 (1 $\mu \mathrm{g} /$ well in $100 \mu \mathrm{l}$ of DPBS) was immobilized onto a microtiter plate and following washing, plasminogen (1 $\mu \mathrm{g} /$ well $)$ was added. After washing, fibrinogen $(1 \mu \mathrm{g} /$ well $)$ and $\mathrm{uPA}(0.1 \mu \mathrm{g} /$ well $)$ were added, and then the mixtures were incubated at $37^{\circ} \mathrm{C}$. Unbound tPA was washed off after incubation with $A$. fumigatus conidia. The reaction was stopped at the indicated time points by addition of $\operatorname{Roti}^{\circledR}$-Load 1 , and proteins were separated by SDS-PAGE and transferred to a membrane. Degraded Fibrinogen was visualized by Western blotting using rabbit antiserum for human fibrinogen, followed by goat HRPconjugated anti-rabbit antibodies.

\section{Degradation of $\mathrm{C} 3$ and $\mathrm{C} 3 \mathrm{~b}$ by Plasmin Bound to AfEno1}

Plasminogen (1 $\mu \mathrm{g} /$ well) was bound to immobilized AfEnol. Plasminogen was pure of fibrinogen. After washing, C3 (1 $\mu \mathrm{g} /$ well $)$ or C3b (1 $\mu \mathrm{g} /$ well $)$ and uPA $(0.1 \mu \mathrm{g} /$ well $)$ were added.
Following incubation the reaction was stopped at different time points with Roti ${ }^{\circledR}$-Load 1, and proteins were subjected to SDSPAGE. After transfer to a membrane, C3 and C3b degradation products were analyzed by Western blotting using goat antiserum raised against human $\mathrm{C} 3$.

\section{Flow Cytometry}

To analyze AfEnol expression on the surface of resting and swollen conidia, the conidia were incubated with rabbit anti-AfEnol antiserum for $1 \mathrm{~h}$. After washing, Alexa fluor ${ }^{\circledR}$. 488 conjugated donkey anti-rabbit antiserum was added. To determine plasminogen binding to resting and swollen conidia, plasminogen at concentrations of $2.5,5$, and $10 \mu \mathrm{g} / \mathrm{ml}$ was added to the conidia $\left(2 \times 10^{6}\right)$ for $1 \mathrm{~h}$ at RT. After washing, goat antiserum raised against human plasminogen was added, followed by Alexa fluor ${ }^{\circledR}-647$ conjugated anti-goat antiserum. After washing, fluorescence conidia were evaluated by flow cytometry (LSR II, BD Biosciences) and median fluorescence intensity (MFI) was analyzed by FlowJo.

\section{Indirect Immunofluorescence Assay for Plasminogen and AfEno1}

Resting conidia $\left(5 \times 10^{6}\right.$ cells $\left./ \mathrm{ml}\right)$ were attached to poly-Llysine pre-coated coverslips for $1 \mathrm{~h}$ at RT. To obtain swollen conidia and hyphae, the resting conidia were incubated on poly-L-lysine pre-coated coverslips for 4 and $8 \mathrm{~h}$, respectively, in RPMI 1640 with $10 \%$ FCS (v/v) at $37^{\circ} \mathrm{C}$. Unbound cells were washed off, and the bound cells were fixed in $4 \%(\mathrm{w} / \mathrm{v})$ paraformaldehyde (PFA) in PBS for $10 \mathrm{~min}$. Following blocking with $3 \%$ BSA for $1 \mathrm{~h}$, plasminogen $(50 \mu \mathrm{g} / \mathrm{ml})$ was added to the fungal cells and the mixture was incubated for $1 \mathrm{~h}$ at RT. After washing, the cells rabbit AfEno1 antiserum (1:100) together with goat antiserum recognizing human plasminogen was added and incubated for $1 \mathrm{~h}$ at RT. Next, fluorochrome conjugated secondary antiserum was added. Following washing, the coverslips were mounted on glass slides with Mount Fluor (Pro Taqs) and images were captured with LSM 710 (Zeiss, Germany), using ZEN 2009 software.

\section{In-gel Fibrinogen Degradation}

In-gel fibrinogen degradation was performed as described (38). Briefly, plasminogen $(10 \mu \mathrm{g} / \mathrm{ml})$ was added to swollen $A$. fumigatus conidia $\left(1 \times 10^{6}\right)$ and then the cells were incubated for $1 \mathrm{~h}$ at RT. Then conidia were washed and tPA $(5 \mu \mathrm{g} / \mathrm{ml})$ was added. In some cases plasmin action was blocked with also the protease inhibitor approtinin $(100 \mu \mathrm{g} / \mathrm{ml})$. After incubation for $1 \mathrm{~h}$ at RT, conidia were washed, the cells were transferred to a pre-formed fibrin matrix gels. Gels were prepared by combining fibrinogen $\left(5 \mathrm{mg} \mathrm{ml}^{-1}\right)$, thrombin $\left(1.25 \mathrm{U} \mathrm{ml}^{-1}\right)$ and plasminogen $(20 \mu \mathrm{g} / \mathrm{ml})$ all dissolved in low melting agarose $(1.25 \%)$ in DPBS. Gels were incubated in a humidified chamber at $37^{\circ} \mathrm{C}$, overnight and in-gel fibrinogen degradation by plasmin bound to swollen conidia was evaluated. After incubation, the cleared agarose circles represent areas were fibrin-matrix fibrinogen was degraded. The diameter of the cleared area correlates directly with the enzymatic activity of plasmin. 


\section{Evaluation of Cell Viability and Determination of Cell Retraction}

sTo determine how swollen conidia having plasmin attached to their surface damages human lung epithelial cells, cell viability was evaluated. Human lung epithelial cells were seeded $\left(5 \times 10^{4} /\right.$ well $)$ in a 96-well plate and the cells were cultivated until reaching confluence. Swollen A. fumigatus conidia $\left(5 \times 10^{6} /\right.$ well $)$ were fixed with $4 \%$ paraformaldehyde (PFA) for $10 \mathrm{~min}$. After washing, the conidia were incubated with plasminogen $(200 \mu \mathrm{g} / \mathrm{ml})$ for $1 \mathrm{~h}$. Following washing, conidia with plasminogen bound were added to the epithelial cell monolayer and the activator tPA $(50 \mu \mathrm{g} / \mathrm{ml})$ was added. In some settings also the serine protease inhibitor approtinin $(100 \mu \mathrm{g} / \mathrm{ml})$ dissolved in FCSfree DMEM was added. The conidia were sedimented onto epithelial cells by centrifugation $(200 \times \mathrm{g}$ for $1 \mathrm{~min})$. After $4 \mathrm{~h}$ incubation at $37^{\circ} \mathrm{C}$ in humidified $5 \% \quad \mathrm{CO}_{2}$ incubator, FCS $(20 \mu \mathrm{l})$ was added to each well, and the cells were incubated overnight at $37^{\circ} \mathrm{C}$. Then the unbound conidia were removed by washing, and resazurin (100 $\mu \mathrm{l})$ (Promega $\mathrm{GmbH}$, Mannheim, Germany) was added and cells were further incubated at $37^{\circ} \mathrm{C}$ for $2 \mathrm{~h}$. Resorufin formation was followed at $570 \mathrm{~nm}$.

Retraction of human epithelial cells from their matrix was assayed microscopically as described $(19,34)$. In brief, human lung epithelial cells were seeded $\left(5 \times 10^{5}\right.$ cells/ well $)$ on coverslips in a 12 -well plate. Swollen conidia having plasminogen attached to their surface $\left(25 \times 10^{6} /\right.$ well $)$ were treated with tPA $(100 \mu \mathrm{g} / \mathrm{ml})$ and added to the confluent epithelia cell monolayer in plain DMEM. The cells were co-incubated in humidified $5 \% \mathrm{CO}_{2}$ incubator at $37^{\circ} \mathrm{C}$ for $2 \mathrm{~h}$. Plasmin activity in some wells was blocked by aprotinin. After incubation for $2 \mathrm{~h}$, unbound cells were washed off, and attached cells were fixed with PFA (4\%) and stained with Texas-Red conjugated Wheat-Germ-Agglutinin $(10 \mu \mathrm{g} / \mathrm{ml}$; Thermo Fisher Scientific) and DAPI $(10 \mu \mathrm{g} / \mathrm{ml})$. The coverslips were mounted on glass slides and evaluated by confocal microscopy. Images were captured with LSM 710 (Zeiss, Germany), using ZEN software. The number of cell free spots formed and the void area was quantified by bioinformatics image analysis as described $(19,34)$.

\section{RESULTS}

\section{Recombinant AfEno1 Binds Factor $\mathrm{H}$ and FHL-1}

In order to analyze the binding repertoire of AfEnol to human complement regulators, A. fumigatus AfEnol was cloned, expressed as a His-tagged protein in E. coli, and purified to homogeneity (Supplementary Figures 1A-C). First, the binding of factor $\mathrm{H}$ and FHL-1 was studied by ELISA. When added to immobilized AfEno1, both factor $\mathrm{H}$ and FHL-1 bound and binding was dose-dependent (Figures 1A,B). This interaction also occurred in a reverse orientation; AfEno1 bound to immobilized factor $\mathrm{H}$ and to FHL1 (Supplementary Figures 2A,B). Also, NHS-derived factor $\mathrm{H}$ bound to AfEno1, and again this binding was dose-dependent (Supplementary Figure 2C).

The AfEno1::factor $\mathrm{H}$ interaction was followed in real time by biolayer interferometry, and the affinity was determined. AfEnol was attached to the Ni-NTA sensor, and factor $\mathrm{H}$ was added as analyte. The association was followed for $250 \mathrm{~s}$, and upon removal of the analyte, the dissociation was followed for another $250 \mathrm{~s}$. The complexes dissociated at a low rate; factor $\mathrm{H}$ bound to AfEnol with a $\mathrm{K}_{\mathrm{D}}$ of $528.5 \mathrm{nM}$ (Figure 1C).

\section{Mapping of AfEno1 Binding Domains in Factor $\mathrm{H}$ and FHL-1}

To localize the binding domains of factor $\mathrm{H}$ and FHL-1, factor $\mathrm{H}$ deletion mutants were added to immobilized AfEno1. Bound deletion mutants were detected with goat human factor $\mathrm{H}$ antiserum. Factor H/FHL-1 deletion fragments factor $\mathrm{H}_{1-6}$, factor $\mathrm{H}_{1-7 \text { SFTL }}=$ FHL-1, factor $\mathrm{H}_{19-20}$ bound to AfEno1; deletion fragments factor $\mathrm{H}_{1-5}$, factor $\mathrm{H}_{8-11}$, factor $\mathrm{H}_{11-15}$, factor $\mathrm{H}_{15-18}$ did not bind (Figures 1D,E). Thus, FHL-1 attaches to AfEnol with one region, and SCR6 seems the major contact site, and factor $\mathrm{H}$ binds to AfEno1 via by two regions, via SCRs67 with SCR6 as major contact site, which is shared with FHL-1, and via SCRs19-20.

\section{Factor $\mathrm{H}$ and FHL-1 Bound to AfEno1 Display Cofactor Activity}

We next investigated the regulatory activity of the AfEnol attached host complement inhibitors. Factor H or FHL-1 was bound to immobilized AfEno1, and, following washing, C3b and factor I were added. Upon incubation for $2 \mathrm{~h}$ at $37^{\circ} \mathrm{C}$, the proteins were separated by SDS-PAGE and transferred to a membrane. $\mathrm{C} 3 \mathrm{~b}$ cleavage fragments were identified by Western blotting. When bound to AfEno1, factor $\mathrm{H}$ assisted in factor I mediated cleavage of the $\alpha^{\prime}$ chain of $\mathrm{C} 3 \mathrm{~b}$ as revealed by the appearance of the $\alpha^{\prime} 68$ and $\alpha^{\prime} 43$ cleavage products. Cleavage was dosedependent (Figure 2A, lanes 3-5). Similarly, FHL-1 bound to AfEno1 assisted in C3b cleavage. In this case $\alpha^{\prime} 68, \alpha^{\prime} 43$, and $\alpha^{\prime} 41$ bands appeared. Also this effect was dose-dependent (Figure $2 \mathbf{B}$, lanes 3-5). Thus, factor H and FHL-1 bound to AfEno1 retrain cofactor activity.

\section{Recombinant AfEno1 Binds Human C4BP, and AfEno1-Bound C4BP Retains Regulatory Activity}

In addition, binding of AfEnol to C4BP was analyzed by ELISA. AfEnol bound to immobilized C4BP and binding was dose-dependent (Figure 3A). Also, NHS-derived C4BP bound to immobilized AfEno1 (Figure 3B). In reverse setting, purified C4BP also bound to immobilized AfEno1 (Supplementary Figure 2D). C4BP::AfEnol interaction was followed in real time. To this end, C4BP was added to immobilized AfEno1, and the association was followed for $250 \mathrm{~s}$. Upon removal of the analyte, the dissociation was followed for the same time. C4BP::AfEnol complexes dissociated at a 
A

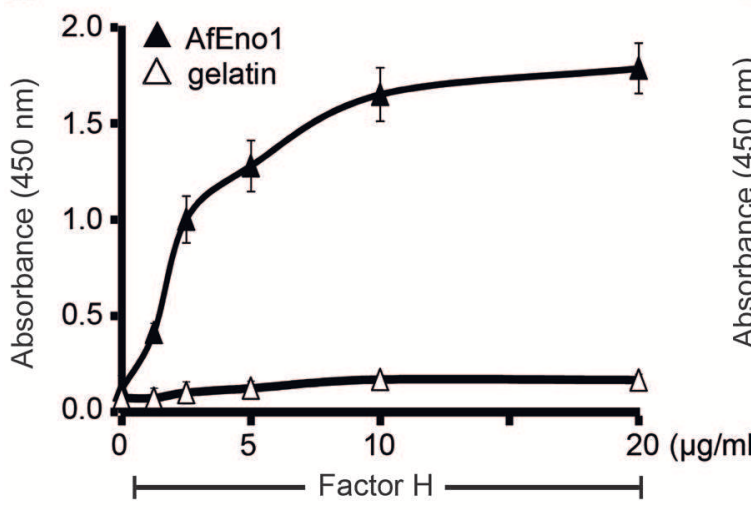

B

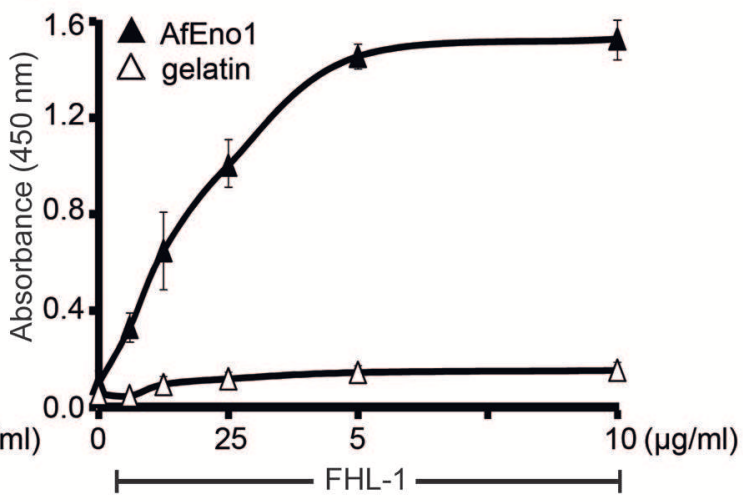

D

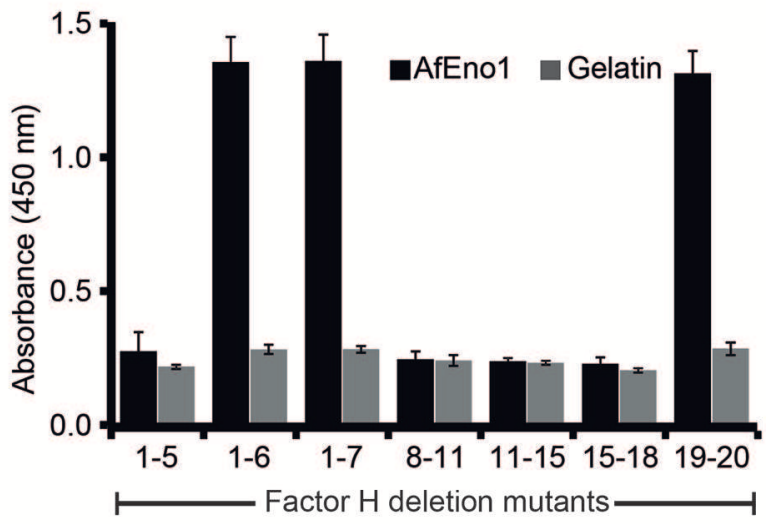

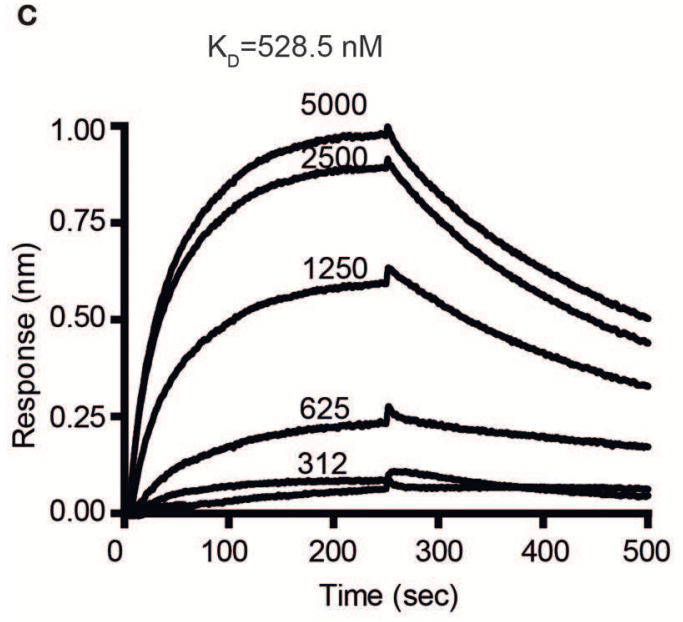

$\mathbf{E}$

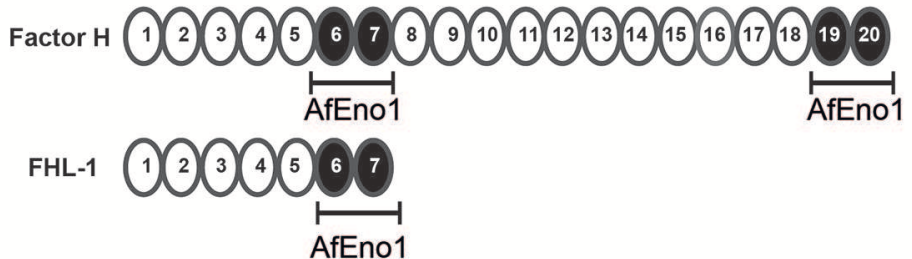

FIGURE 1 | Factor $\mathrm{H}$ and factor-H-like protein 1 (FHL-1) bind to Aspergillus fumigatus enolase (AfEno1). (A) Factor $\mathrm{H}$ binds to AfEno1 dose dependently. Factor $\mathrm{H}$ binding to Aspf2 was assayed by enzyme-linked immunosorbent assay (ELISA). AfEno1 was immobilized onto a microtiter plate, and factor $\mathrm{H}$ at increasing amounts was added. After washing, bound factor $\mathrm{H}$ was detected with goat human factor $\mathrm{H}$ antiserum. Factor $\mathrm{H}$ did not bind to gelatin. (B) FHL-1 binds to AfEno1 dose dependently. FHL-1 at indicated amounts was added to immobilized FHL-1, and bound FHL-1 was detected with goat human factor $\mathrm{H}$ antiserum. FHL-1 showed no binding to gelatin. (C) Factor $\mathrm{H}$ binds to AfEno1 with high affinity. The affinity of factor $\mathrm{H}$ to AfEno1 was evaluated by biolayer interferometry. Factor $\mathrm{H}$ at indicated concentrations $(312,625,1250,2,500$, and 5,000 nM) was added to AfEno1 immobilized to the Ni-NTA sensor. The association was followed for $250 \mathrm{~s}$, and upon removal of the analyte, the dissociation followed another $250 \mathrm{~s}$. Factor $\mathrm{H}$ binds to AfEno1 with a $K_{\mathrm{D}}=528.5 \mathrm{nM}$. Heat-inactivated $\left(95^{\circ} \mathrm{C}\right)$ factor $\mathrm{H}$ showed no binding to AfEno1 (bottom line). The experiments were repeated three times in independent assays. The results show similar association and dissociations profiles and revealed the same affinities. (D) Mapping of AfEno1-binding regions within factor $\mathrm{H}$ and FHL-1 by ELISA. Factor $\mathrm{H} / \mathrm{FHL}-1$ deletion mutants were added to immobilized AfEno1, and bound factor $\mathrm{H} / \mathrm{FHL}-1$ deletion mutants were detected by goat human factor $\mathrm{H}$ antiserum. AfEno1 attaches to factor $\mathrm{H}$ via short consensus repeats (SCRs) 6-7 and 19-20 and to FHL-1 via SCRs 6-7. (E) Schematic representation of SCR of factor H and FHL-1. AfEno1 binding domains of factor H (upper) and FHR-1 (lower) are highlighted in black. (A,B,D) show mean values \pm SD of three separate experiments. 

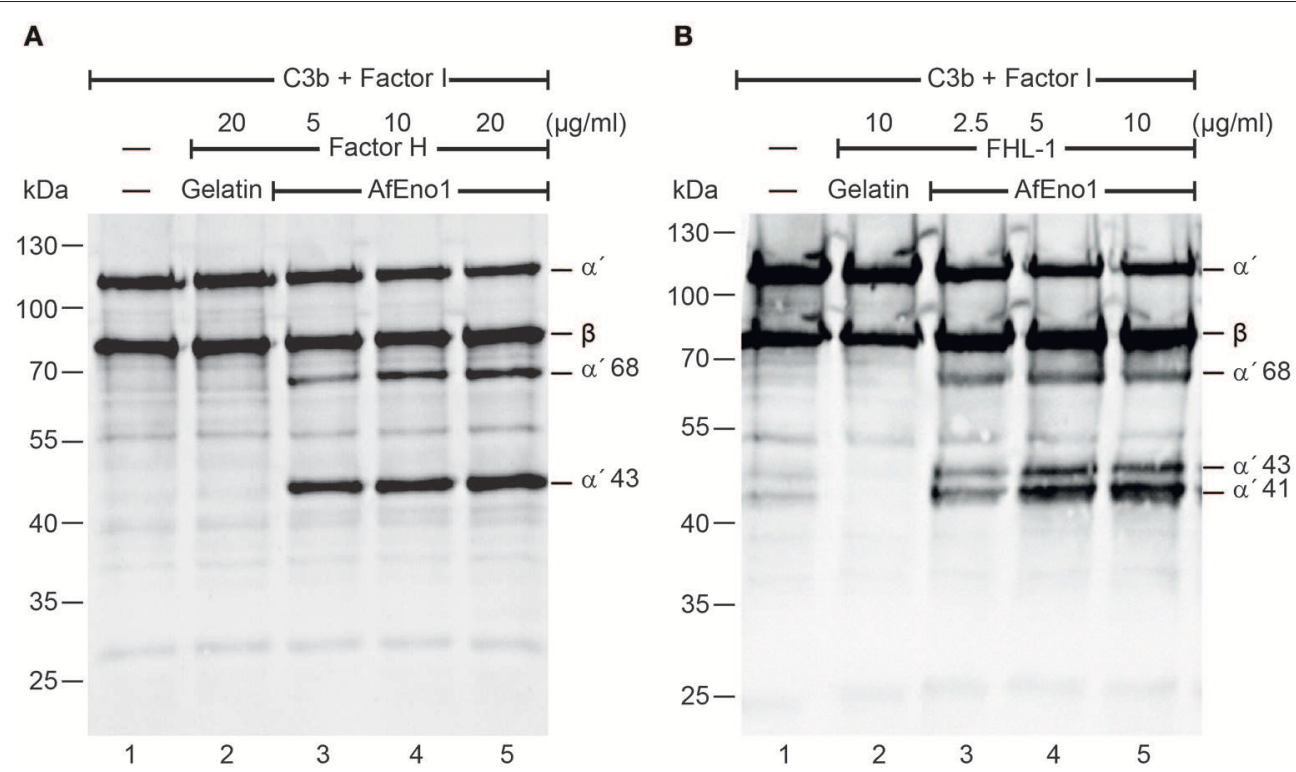

FIGURE 2 | Factor $\mathrm{H}$ and factor-H-like protein 1 (FHL-1) bound to Aspergillus fumigatus enolase (AfEno1) maintain regulatory activity. (A) Factor H at indicated amounts was attached to immobilized AfEno1. After washing, C3b and factor I were added for $2 \mathrm{~h}$ and were separated by SDS-PAGE. C3b cleavage products were identified by western blotting with goat human $\mathrm{C} 3$ antiserum. Factor $\mathrm{H}$ bound to AfEno1 mediated C3b cleavage by factor I, and C3b cleavage products $\alpha^{\prime} 68$ and $\alpha^{\prime} 43 \mathrm{kDa}$ were identified dose dependently (lanes 3-5). When factor $\mathrm{H}$ was added to the negative control gelatin, no C3b cleavage products were observed (lane 2). (B) FHL-1 at increasing amounts was attached to AfEno1. Following washing, C3b and factor I were added for $2 \mathrm{~h}$; the proteins were subjected to SDS-PAGE. After being transferred to a membrane, C3 cleavage products were visualized by western blotting. FHL-1 assisted in C3b cleavage by factor I, as revealed by the appearance of C3b cleavage products $\alpha^{\prime} 68, \alpha^{\prime} 43$, and $\alpha^{\prime} 41$ (lanes 3-5). No C3b cleavage products were observed in the negative control gelatin (lane 2). Data shown in $\mathbf{( A )}$ and $\mathbf{( B )}$ are one representative result of three independent experiments.

low rate. C4BP bound to AfEnol with affinity of $\mathrm{K}_{\mathrm{D}} 131.1 \mathrm{nM}$ (Figure 3C).

We further assessed whether the regulatory activity of $\mathrm{C} 4 \mathrm{BP}$ attached to AfEno1. C4b and factor I were added to preformed C4BP::AfEno1 complexes. After incubation at $37^{\circ} \mathrm{C}$ for $4 \mathrm{~h}$, the proteins were separated by SDS-PAGE, transferred to a membrane and $\mathrm{C} 4 \mathrm{~b}$ cleavage was followed. $\mathrm{C} 4 \mathrm{BP}$ bound to AfEnol acted as cofactor for C4b degradation, and the $\alpha^{\prime} 70$ and $\alpha^{\prime} 15$ cleavage bands of the $\alpha^{\prime}$ chain appeared (Figures 3C,D, lanes 2-4).

\section{AfEno1 Binds to Human Plasminogen via Lysine Residues}

AfEno1 binds immobilized plasminogen (Figure 4A) (42). The interaction also occurred in reverse orientation. Plasminogen bound to immobilized AfEno1, and this binding was dosedependent (Figure 4B). Moreover, serum derived plasminogen bound to immobilized AfEno1; again in a dose-dependent manner (Figure 4C). The binding of plasminogen to AfEnol was followed in real time. Plasminogen bound to AfEno1; binding was saturated after about $50 \mathrm{~s}$, and the complex dissociated at a slow rate. Plasminogen bound to AfEnol with a $\mathrm{K}_{\mathrm{D}}$ of $530 \mathrm{nM}$ (Figure 4D).

As many microbial proteins bind plasminogen via lysine residues, we asked if the lysine analog $\varepsilon$-aminocaproic acid ( $\varepsilon$-ACA) influences the interaction. $\varepsilon$-ACA inhibited plasminogen binding to AfEnol, and the effect was dose-dependent. At $2.5 \mathrm{nM}$-ACA blocked binding completely (Figure 4E). In addition, lysine, but neither arginine nor glutamic acid blocked plasminogen binding to AfEno1 (Figure 4F). Thus, AfEnol binds to plasminogen via lysine residues.

\section{Plasminogen Bound to AfEno1 Is Accessible for Activators}

Plasmin degrades complement proteins and extracellular matrix components (19). To assess the role of plasminogen bound to AfEnol for immune evasion and tissue invasion, the zymogen was treated with the activator tPA. AfEnol bound plasminogen when treated with tPA was converted to plasmin, which cleaved the chromogenic substrate S-2251 and cleavage was time-dependent (Figure 5A). No proteolytic activity was detected when the interaction was blocked by $\varepsilon$-ACA or in presence of aprotinin (Figure 5A). Plasmin bound to AfEno1 also degraded the physiological substrate fibrinogen. This degradation was time-dependent, and, after $2 \mathrm{~h}$, fibrinogen was completely degraded (Figure 5B). Furthermore, plasmin bound to AfEno1 cleaved C3, as shown by appearance of $\alpha 68, \alpha 46$, $\alpha 40, \alpha 30$, and $\alpha 27 \mathrm{kDa}$ bands (Figure 5C, lanes 2-7). Also, this cleavage was time dependent. Similarly, plasmin bound to AfEnol cleaved C $3 \mathrm{~b}$ as visualized by appearance of $\alpha^{\prime} 68, \alpha^{\prime} 46$, $\alpha^{\prime} 40, \alpha^{\prime} 30$, and $\alpha^{\prime} 27 \mathrm{kDa}$ bands (Figure 5D, lanes 2-6). Thus, plasminogen bound to AfEno1 is accessible for tPA and activated to plasmin. 

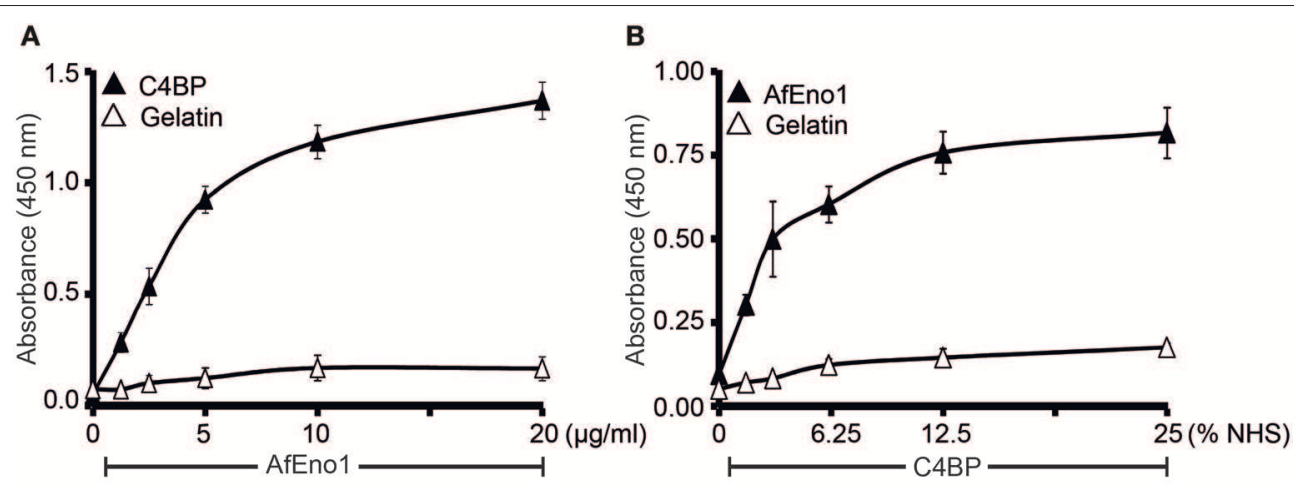

C

D
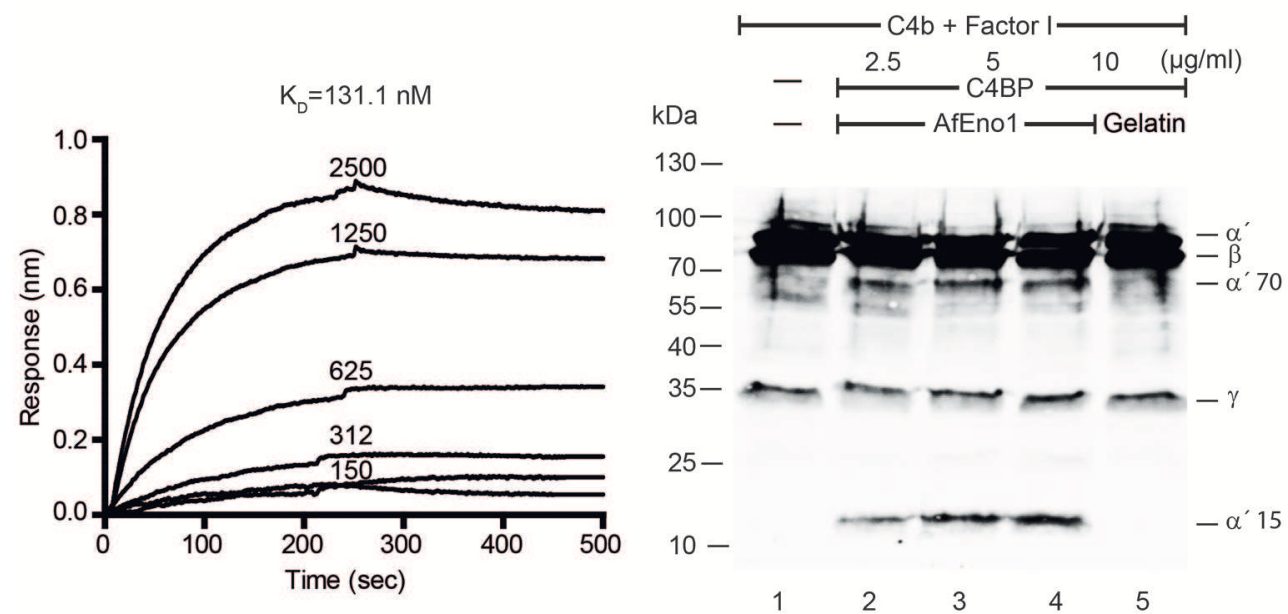

FIGURE 3 | C4b binding protein (C4BP) binds to Aspergillus fumigatus enolase (AfEno1), and AfEno1-bound C4BP retains regulatory activity. (A) AfEno1 was immobilized onto a microtiter plate overnight, and C4BP at increasing amounts was added. After washing, bound C4BP was detected with goat human C4BP antiserum. C4BP showed no binding to gelatin. (B) Plasma-derived C4BP binds to AfEno1 dose dependently. Normal human serum (NHS) (10 mM EDTA) at different concentrations was added to immobilize AfEno1, and bound C4BP was detected as above. (C) The binding affinity of C4BP with AfEno1 was evaluated by biolayer interferometry. C4BP at the indicated concentrations (150, 312, 625, 1,250, and 2,500 nM) was bound to AfEno1 immobilized on Ni-NTA sensor surfaces. For each concentration, the association was followed for $250 \mathrm{~s}$, and upon removal of the analyte, the dissociation followed another $250 \mathrm{~s}$. C4BP binds to AfEno1 with a $K_{\mathrm{D}}=$ $131.1 \mathrm{nM}$. (D) C4BP bound to AfEno1 retained cofactor activity. C4BP at indicated amounts was attached to immobilized AfEno1. After washing, C4b and factor I were added for $4 \mathrm{~h}$, and the proteins were separated by SDS-PAGE. After being transferred to the membrane, C4b cleavage products were visualized by western blotting with goat human C4 antiserum. C4BP bound to AfEno1 assisted in cleavage of C4b by factor I, and C4b cleavage products $\alpha^{\prime} 70$ and $\alpha^{\prime} 15$ were identified dose dependently (lanes 2-4). No C4b cleavage products were observed in the negative control gelatin (lane 5). (A,B) Are mean \pm SD of three independent experiments. (D) Represents one of three independent experiments.

\section{AfEno1 Is Expressed on the Surface of Swollen Conidia and Hyphae and Colocalizes With Plasminogen}

AfEno1 expression on the surface of resting and swollen conidia was evaluated by flow cytometry. AfEno1 was not identified on the surface of resting A. fumigatus conidia (Figure 6A), but was identified on the surface of swollen conidia (Figure 6B). AfEno1 was identified at high levels on the surface of swollen conidia and hyphae as shown by confocal microscopy (Figure 6C, upper panel I). AfEno1 (green fluorescence) was evenly distributed on the surface of both swollen conidia (Figure 6C, middle panel I) and hyphae (Figure 6C, lower panel I). Thus, AfEnol is expressed on the surface of swollen conidia and hyphae, but not on resting conidia.
In addition, plasminogen (red fluorescence) distribution was evaluated. Plasminogen bound to all three morphotypes. Plasminogen colocalized with AfEnol on the surface of swollen conidia (Figure 6C, middle panel IV) and hyphae (Figure 6C, lower panel IV). Plasminogen binding to resting conidia, which lack AfEnol shows that A. fumigatus expresses additional plasminogen binding surface proteins.

\section{Resting Conidia Bind Less Plasminogen Than Swollen Conidia}

We next compared the intensity of plasminogen binding to resting and swollen conidia. Plasminogen bound dosedependently to both morphotypes. Plasminogen used at $2.5 \mu \mathrm{g} / \mathrm{ml}$ bound with high intensity to swollen conidia 
A

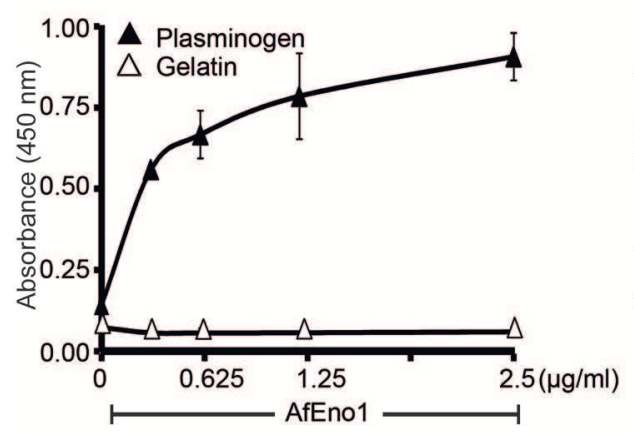

C

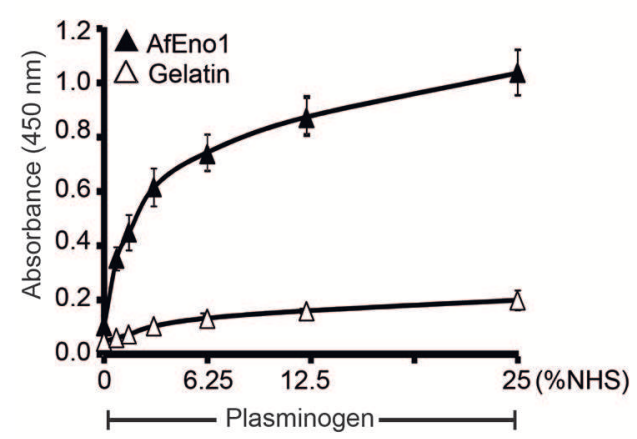

E

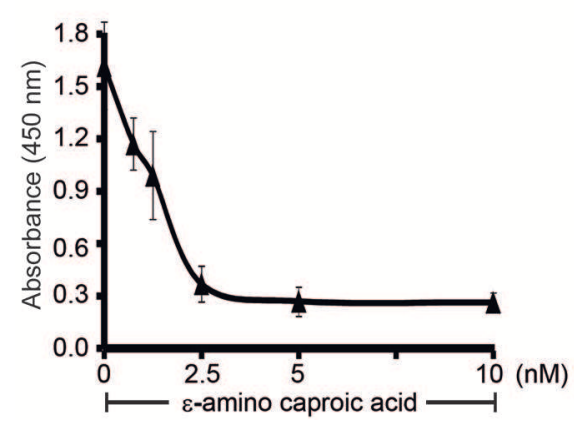

B

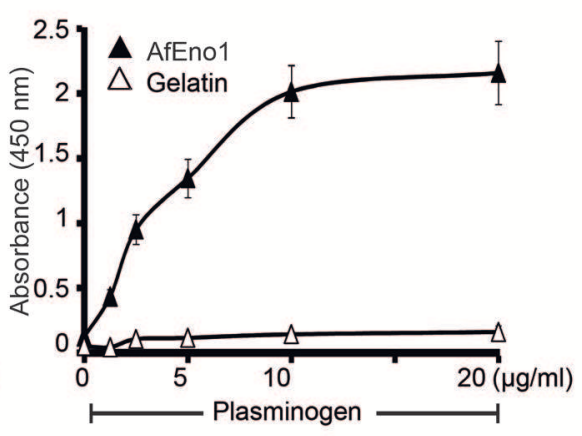

D

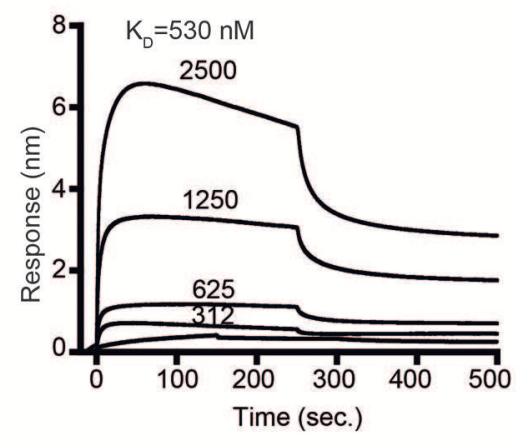

F

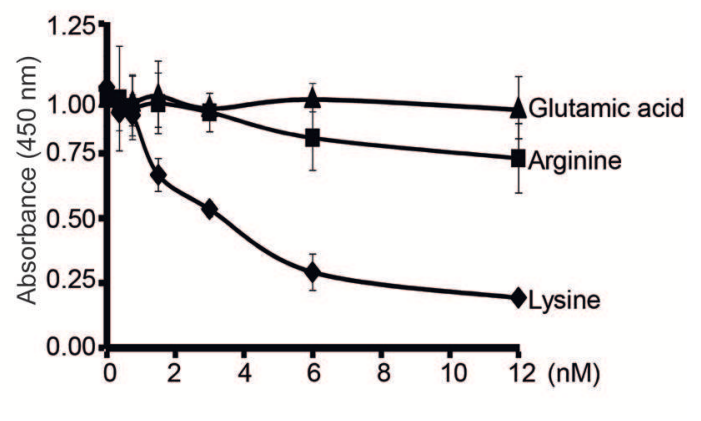

FIGURE 4 | Plasminogen binds to Aspergillus fumigatus enolase (AfEno1) via lysine residues. (A) AfEno1 binding to plasminogen was assayed by enzyme-linked immunosorbent assay (ELISA). AfEno1 at indicated amounts was added to immobilized plasminogen, and bound AfEno1 was detected with rabbit AfEno1 antiserum. AfEno1 bound to plasminogen dose dependently. AfEno1 did not bind to gelatin. (B) Plasminogen binds to AfEno1. Plasminogen at increasing amounts was added to immobilized AfEno1, and bound plasminogen was detected with goat human plasminogen antiserum. AfEno1 showed no binding to gelatin. (C) AfEno1 recruits plasminogen from serum. Normal human serum (NHS) (10 mM EDTA) at different concentrations was added to immobilize AfEno1, and bound plasminogen was detected as above. (D) The binding affinity of plasminogen to AfEno1 was evaluated by biolayer interferometry. Plasminogen at different concentrations (312, 625, 1,250, and 2,500 nM) was added to AfEno1 immobilized on Ni-NTA biosensors. For each concentration, the association was evaluated for $250 \mathrm{~s}$. Following removal of the analyte, the complex dissociation was assessed for another $250 \mathrm{~s}$. Plasminogen binds to AfEno1 with a $K_{\mathrm{D}}=530 \mathrm{nmol} / \mathrm{L}$. Heat-inactivated $\left(95^{\circ} \mathrm{C}\right)$ plasminogen showed no binding to AfEno1 (bottom line). (E) The lysine analog $\varepsilon$-ACA blocks plasminogen binding to AfEno1. $\varepsilon$-ACA, at the indicated concentrations, was incubated with plasminogen for $30 \mathrm{~min}$, and the mixture was added to immobilized AfEno1. The bound plasminogen was detected with goat human plasminogen antiserum. (F) The effect of free amino acids on plasminogen binding to AfEno1 was assayed by ELISA. Lysine, arginine, or glutamic acid at increasing concentrations were added to plasminogen, and the mixture was added to immobilized AfEno1. The bound plasminogen was detected as above. Lysine blocked plasminogen bonding to AfEno1. However, arginine and glutamine acid had no effect on plasminogen binding to AfEno1.

$(\mathrm{MFI} ; 2,583 \pm 323)$ as to resting conidia (MFI; 661 $\pm 150 ;$ mean \pm SD, $P<0.0007)$. Thus, plasminogen bound to resting conidia with $74 \%$ lower intensity (Figure 6D).

\section{Plasmin Bound to Swollen Conidia Degrades Fibrinogen}

To analyze the effect of plasmin attached to A. fumigatus conidia, we next investigated whether plasmin-attached to 
A

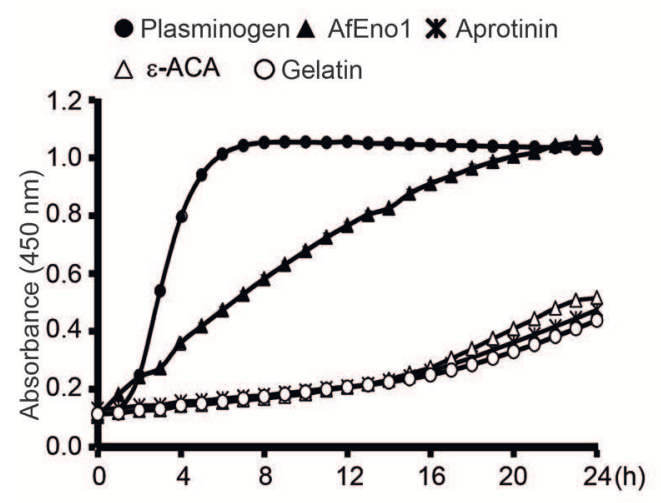

B

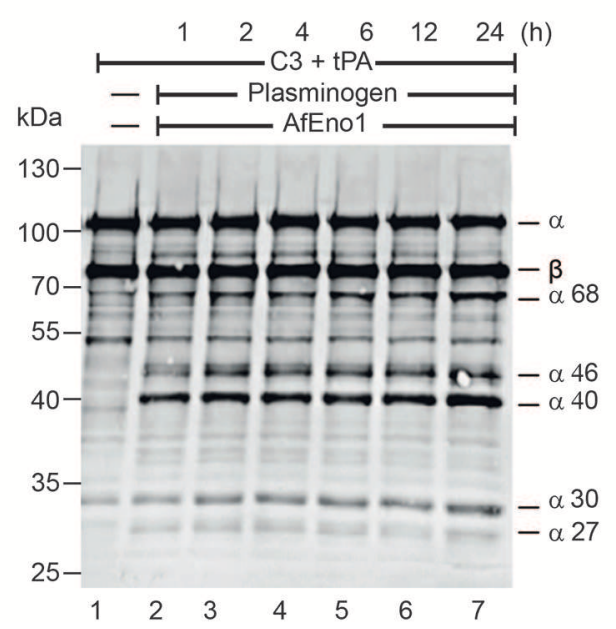

C

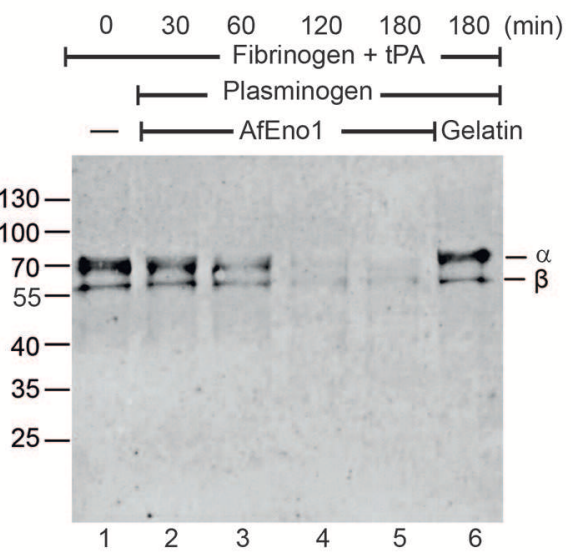

D

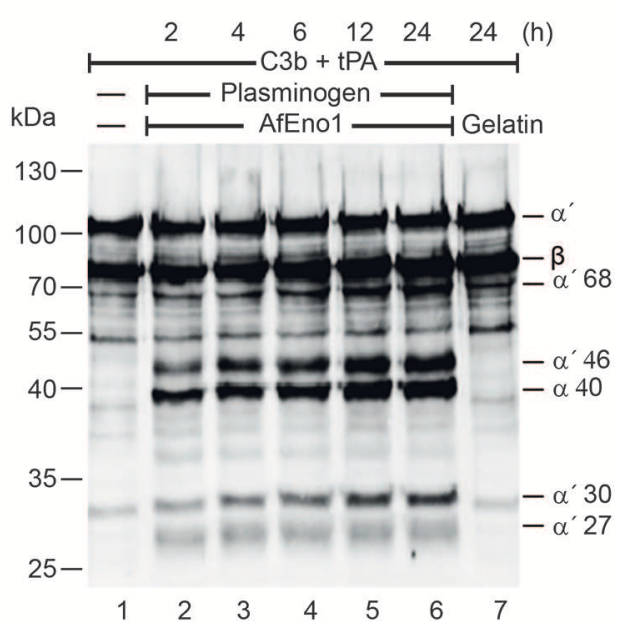

FIGURE 5 | Plasminogen bound to Aspergillus fumigatus enolase (AfEno1) is available for the activators. (A) Plasminogen was added to immobilized AfEno1 on a microtiter plate for $1 \mathrm{~h}$. After washing, the urokinase-type plasminogen activator (UPA) and the chromogenic substrate S-2251 were added. The plasmin activity was photometrically red at $405 \mathrm{~nm}$ for every $30 \mathrm{~min}$, over $24 \mathrm{~h}$. AfEno1-bound plasminogen was converted to plasmin, which cleaved the substrate S-2251 time dependently. $\varepsilon$-Aminocaproic acid ( $\varepsilon$-ACA) and aprotinin inhibited S-2251 cleavage. No cleavage of S-2251 occurred in the negative control gelatin. (B) Fibrinogen and tissue-type plasminogen activator (tPA) were added to the preformed AfEno1-plasminogen complex. The reactions were stopped at indicated time points, and the proteins were subjected to SDS-PAGE. Fibrinogen degradation was visualized by Western blotting with a rabbit human fibrinogen antiserum. AfEno1-bound plasminogen was activated to plasmin which cleaved fibrinogen (lanes 2-5). No fibrinogen degradation was visualized in the negative control gelatin (lane 6). (C) C3 and tPA were added to the preformed AfEno1-plasminogen complex. The reaction was stopped at different time points, and the proteins were subjected to SDS-PAGE. C3 degradation products were visualized by western blotting with goat human C3 antiserum. Plasminogen bound to AfEno1 was activated to plasmin which cleaved C3 (lanes 2-7). (D) AfEno1 was immobilized on a microtiter plate, and after washing, C3b and tPA were added. The reaction was stopped indicated time points, and the proteins were separated by SDS-PAGE. C3b cleavage products were determined as above. AfEno1-bound plasminogen was converted to active plasmin which degraded C3b (lanes 2-7). One representative result of three independent experiments is shown in each panel.

swollen conidia degrades a fibrinogen matrix. Swollen conidia lacked fibrinolytic activity; the fibrinogen matrix remained intact and turbid (Figure 6E, panel 1). Similarly, swollen conidia with plasminogen attached and in the absence of tPA lacked a fibrinolytic activity (Figure 6E, panel 3). However, in presence of tPA, newly generated plasmin degraded the fibrin matrix, as revealed by the clear transparent zone (Figure 6E, panel $4)$. Fibrinogen degradation was blocked by the serine protease inhibitor aprotinin (Figure 6E, panel 2).

\section{Plasmin Bound to Swollen Conidia Damages Human Lung Epithelial Cells}

Next we assayed if plasmin attached to swollen conidia influences the integrity of human epithelial cells. First, plasminogen-coated conidia were added to human lung epithelial cells. Following incubation, the metabolic activity of the human cells was determined. Plasmin-attached swollen conidia damaged human A549 epithelial cells, and the metabolic activity was reduced by $41 \%(P<0.0002)$ (Figure 7A, column 3$)$. The metabolic activity 
A

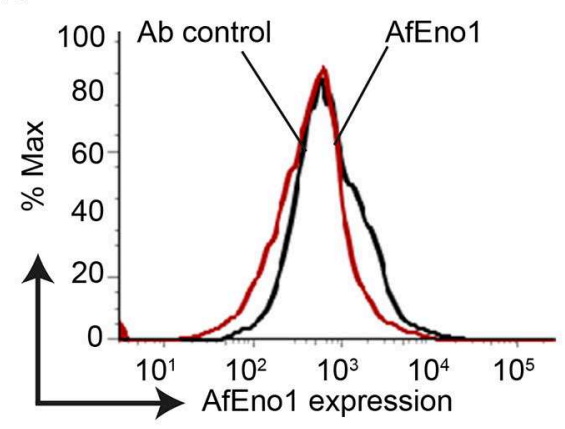

B

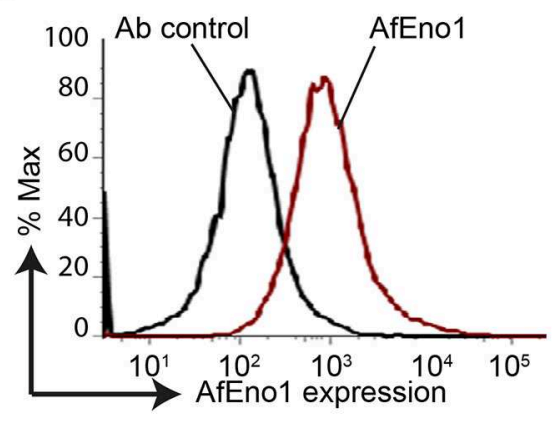

C

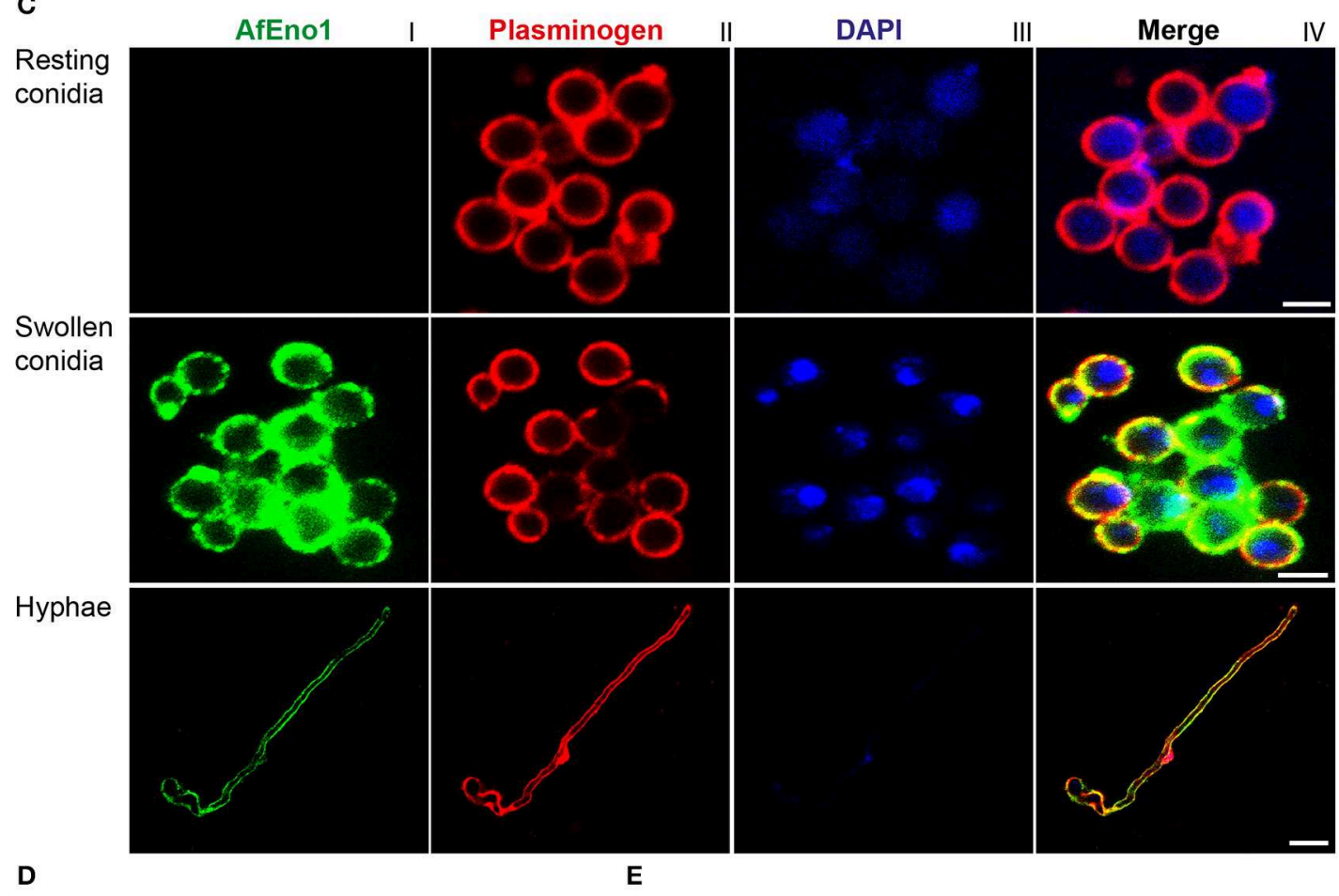

D
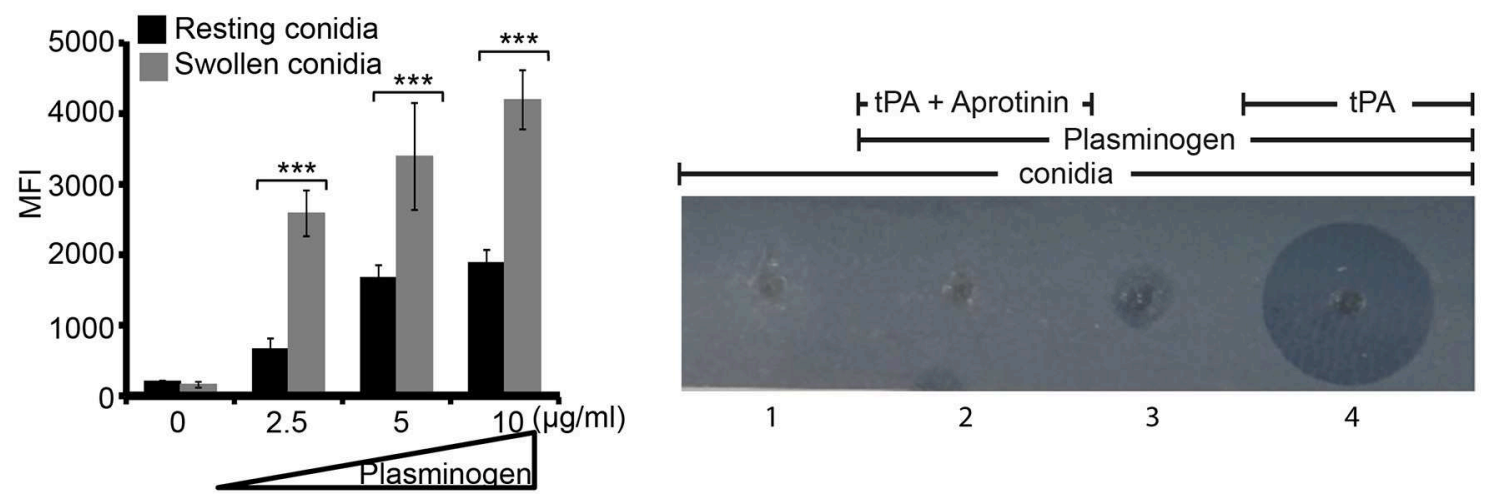

FIGURE 6 | Plasminogen binds to Aspergillus fumigatus enolase (AfEno1) on the surface of A. fumigatus. Analysis of AfEno1 expression by flow cytometry. Resting conidia (A) and swollen conidia (B) were incubated with rabbit AfEno1 antiserum, followed by secondary antibodies. The cells were analyzed by flow cytometry. AfEno1 was absent on the surface of resting conidia but present on the surface of swollen conidia. (C) Plasminogen and AfEno1 colocalize on the surface of swollen conidia and hyphae. Purified plasminogen was added to resting conidia, swollen conidia, and hyphae. After washing, the cells were incubated with goat human 
FIGURE 6 | plasminogen antiserum and rabbit AfEno1 antiserum, followed by corresponding secondary antibodies. AfEno1 was not expressed on the surface of resting conidia (upper pane/). AfEno1 and plasminogen were colocalized on the surface of swollen conidia (middle panel) and hyphae (lower panel). Scale bars 2 , 5 , and $10 \mu \mathrm{m}$ in upper, middle, and lower panels, respectively. (D) Resting conidia binds less plasminogen. Plasminogen at different amounts was incubated with resting and swollen conidia. After washing, the bound plasminogen was analyzed by flow cytometry with goat human plasminogen antiserum, followed by secondary antibodies. ${ }^{\star \star \star} P<0.001$. (E) Plasmin bound to conidia degrades fibrinogen in gel. Plasminogen was bound to swollen conidia, and after washing, swollen conidia were placed in the wells of matrix gel in the presence or absence of tissue-type plasminogen activator (tPA) and the protease inhibitor aprotinin.

of intact cells was set $100 \%$ (Figure 7A, column 6). This effect by plasmin was blocked by the aprotinin (Figure 7A, column 4).

Next the effect on cell integrity and epithelial cell surface retraction was followed. Swollen conidia with surface attached plasminogen/plasmin were added to the epithelial monolayers. Upon incubation, cell retraction was evaluated by microscopy, and both number and area of the void spots was counted. Plasmin attached to swollen conidia induced cell retraction resulting in exposure of the underlying matrix (Figure 7B, panel III). Aprotinin blocked cell retraction (Figure 7B, panel IV). In addition, the number of spots formed and the total area of void spots was quantified by bioinformatic evaluation. Active plasmin attached to the surface swollen conidia caused cell retraction and both the number of void spots and the area of these spots was larger than spots formed by swollen conidia alone, or swollen conidia with plasminogen bound (Figure 7C).

\section{DISCUSSION}

Here, we identify enolase, AfEno1 also known as allergen Aspf22 as the second plasma regulator binding protein of the human pathogen A. fumigatus. AfEno1 binds four human plasma proteins factor $\mathrm{H}, \mathrm{FHL}-1, \mathrm{C} 4 \mathrm{BP}$, and plasminogen. AfEno1 binds factor $\mathrm{H}$ with a $\mathrm{K}_{\mathrm{D}} 528.5 \mathrm{nM}$, C4BP with $\mathrm{K}_{\mathrm{D}} 131.1 \mathrm{nM}$ and plasminogen with $K_{D} 530.0 \mathrm{nM}$. This affinity is comparable to that of the other A. fumigatus factor $\mathrm{H}$ ligand Aspf2 and the C. albicans homolog Pra1. Aspf2 binds factor $\mathrm{H}$ with slightly higher $\left(\mathrm{K}_{\mathrm{D}} 76 \mathrm{nM}\right)$ and plasminogen with similar affinity $\left(\mathrm{K}_{\mathrm{D}} 846 \mathrm{nM}\right)$ (34). However, C. albicans Pral binds factor $\mathrm{H}$ with higher affinity $\left(\mathrm{K}_{\mathrm{D}} 1.87 \mathrm{nM}\right)$ (data not shown).

Factor $\mathrm{H}$ and FHL-1 bound to AfEno1 assist the protease factor I in C3b inactivation. Similarly, C4BP bound to AfEno1 retains regulatory activity and assists for $\mathrm{C} 4 \mathrm{~b}$ inactivation. Plasminogen bound to AfEnol, when activated by tPA, cleaves the substrates S2251, fibrinogen, and degrades C3 and C3b.

AfEno1 binds factor H via SCRs6-7 and SCRs19-20 and FHL1 via SCRs6-7. These domains represent common binding sites for microbial immune evasion proteins (48). These multiple microbial factor $\mathrm{H}$, FHL-1 ligands, despite their common binding features, lack conserved sequence motifs (48). Factor $\mathrm{H}$ and FHL1 use the same regions i.e., SCRs6-7 (factor $\mathrm{H}$ and FHL-1), and SCR19-20 (factor H) bind to modified self surfaces, such as necrotic and damaged human cells e.g., via glycosaminoglycans (GAGs), or modified surface constituents, like Malondialdehyde or phosphatidyl choline (49).

AfEno1 is a 438 -amino-acid moonlighting protein which shares $72.6 \%$ amino acid homology with C. albicans enolase and which is also highly related to enolase from the microbial pathogens Streptococcus pneumoniae, Borrelia burgdorferi,
Staphylococcus aureus, and Paracoccidioides brasiliensis (3739, 41, 50). Given the sequence homology of AfEnol with Candida enolase and with other microbial enolases and their functional homology in moonlighting it will be of interest to evaluate if all these microbial proteins, share the same immune evasion features.

Hijacking human plasminogen by fungal and microbial pathogens is a common mechanism as active plasmin promotes cell adhesion, degrades cell layers, and matrices allowing dissemination during infection $(39,51)$. Acquisition of plasminogen by surface expressed enolase has been show for several pathogens, including the fungal pathogens, $A$. fumigatus, C. albicans, and for the microbial pathogens $B$. burgdorferi, Paracoccidioides brasiliensis and Pneumocystis carinii $(38,39,41,52)$.

AfEnol is expressed on the surface of swollen conidia and hyphae, but not on resting conidia. In contrast, Aspf2, the second A. fumigatus factor $\mathrm{H}$ - and plasminogen ligand which is the homolog of the C. albicans immune evasion protein Pral is expressed on the surface of resting. The $74 \%$ stronger binding of plasminogen to swollen conidia, indicates that A. fumigatus, similar to C. albicans expresses additional plasminogen ligands (34).

Enolase is found at several sites and this moonlighting protein displays location specific functions. Cytoplasmic enolase catalyzes the conversion of 2-phosphoglycerate to phosphoenolpyruvate, surface exposed enolase binds human immune regulators and secreted enolase mediates immune evasion $(42,53)$. Enolase proteins from these pathogenic microbes lack typical signal-peptides, indicating that these proteins are secreted by an novel, unconventional mechanism (54). It is also unclear how enolase is anchored or integrated into the membrane or cell wall of A. fumigatus and of other pathogenic microbes. However, fungal moonlighting proteins including enolase are present in extracellular vesicles released by C. albicans (55). But, to the best of our knowledge, whether $A$. fumigatus releases any extracellular vesicles and the proteome of such extracellular vesicles has not yet been described.

Plasminogen together with complement components and regulators including factor $\mathrm{H}$ FHL-1 are present in the bronchoalveolar lavage fluids $(7,56)$. Thus, by reaching the alveoli and by hijacking these host proteins, A. fumigatus can control human complement attack and can use plasmin for cell damage and tissue destruction. Plasmin, the active protease, attached to swollen conidia inhibit complement, damage human epithelial cells, and degrade the ECM matrix. Such tissue destruction allows invasion and dissemination. Given these central features in immune evasion, enolase is considered $A$. fumigatus a central virulence factors. 
A

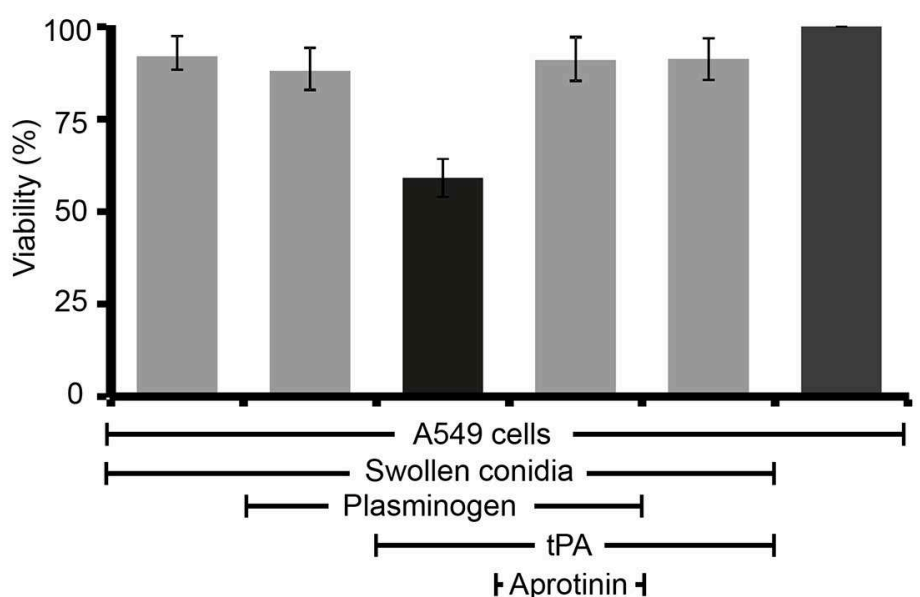

B

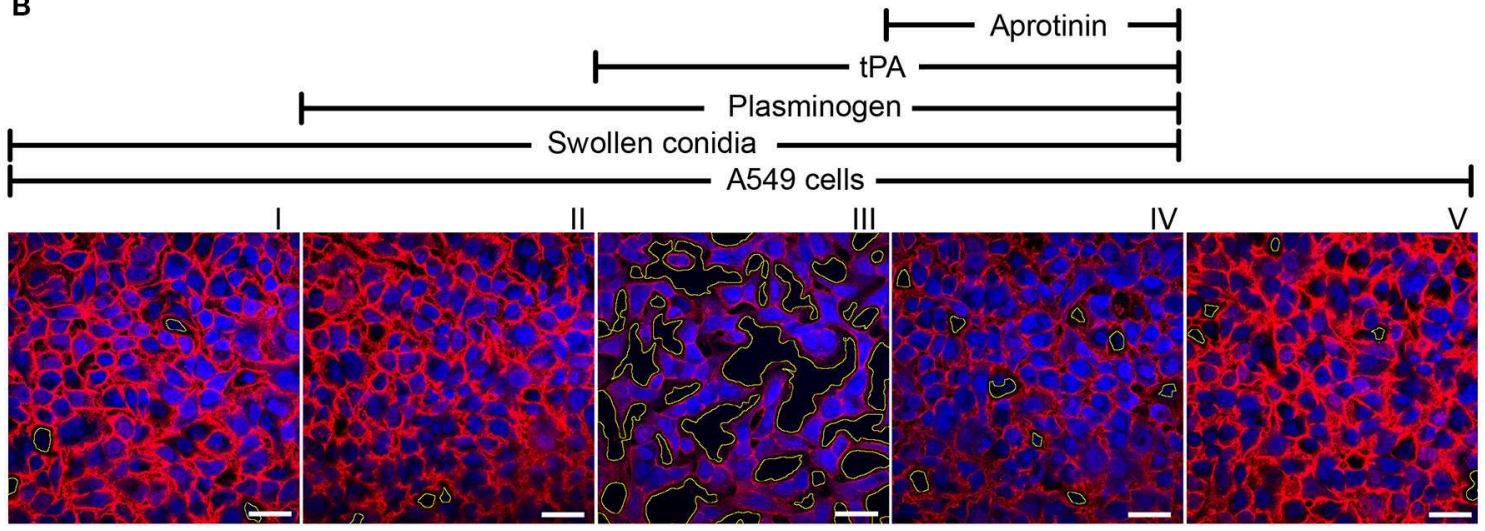

C

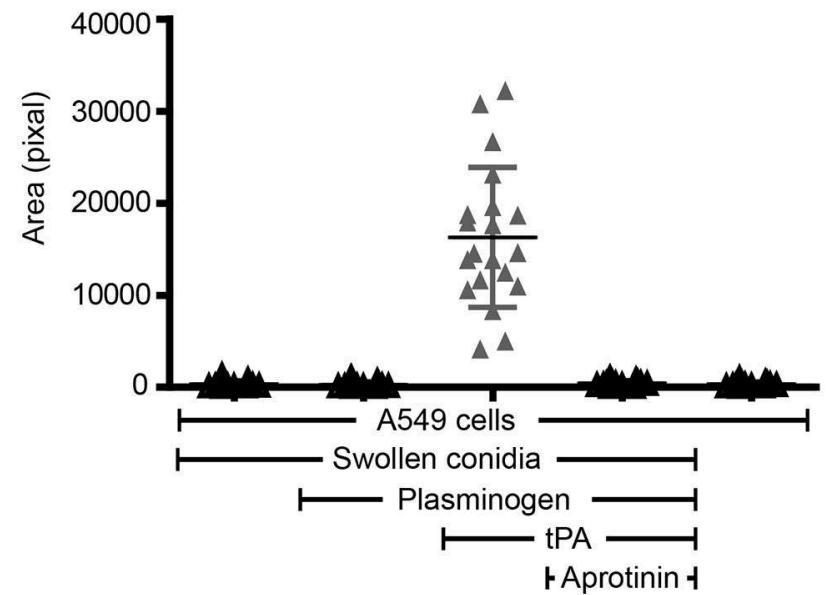

FIGURE 7 | Swollen conidia-bound plasmin damages human A549 cells and induces cell retraction. (A) When activated to plasmin, plasminogen bound to swollen conidia damages human lung epithelial cells. Plasminogen was incubated with swollen conidia. After washing, swollen conidia were added to the monolayer of A549 cells with/without tissue-type plasminogen activator (tPA) for $24 \mathrm{~h}$. After removal of the unbound swollen conidia, the cellular metabolic activity was determined by adding CellTiter-Blue ${ }^{\circledR}$. Plasmin bound to swollen conidia decreased the metabolic activity of lung epithelial cells (column 3). This effect was inhibited by aprotinin (column 4). tPA alone has no effect on the metabolic activity of epithelial cells (column 5). Viability of human A549 cells (column 6). (A) is mean \pm SD of three independent experiments. (B) Plasmin-attached swollen conidia induce cell retraction. Swollen conidia attached to plasminogen were added to the monolayer of 
FIGURE 7 | human lung epithelial cells in the presence and absence of tPA for $2 \mathrm{~h}$. After removal of the unbound conidia, cells were fixed and stained with Texas Red-conjugated wheat germ agglutinin (WGA) (red) and 4',6-diamidino-2-phenylindole (DAPI) (blue). Plasmin bound to conidia induced cell retraction leading to the exposure of the extracellular matrix component. This plasmin activity was blocked by aprotinin. The area of each void spot was identified by automated image analysis and was shown in the images by green borders. Scale bars: $30 \mu \mathrm{m}$. (C) Quantification of epithelial cell damage and retraction by bioinformatics approach. The total void area of each confocal image (20 images) was quantified with novel bioinformatics image analysis. Plasmin bound to the surface of swollen conidia caused more total void area per image than the plasminogen bound to swollen conidia. Aprotinin inhibited plasmin-mediated cell damage. Horizontal bar represents mean, and vertical bar shows SD.

At present two factor $\mathrm{H}$ ligands are identified from $A$. fumigatus, AfEno1 and Aspf2 which both are also identified as allergens (34). Sera from patients with ABPA have AfEno1 reacting $\operatorname{IgE}$ antibodies $(53,57,58)$. AfEnol modulates $\mathrm{T}$ cell response in healthy human individuals (53), but how exactly AfEno1 sensitizes the allergic $\mathrm{T}$ cells is unknown. For C. albicans four factor $\mathrm{H}$ binding proteins are so far identified i.e., pH-regulated antigen 1 (Pra1), glycerol3-phosphate dehydrogenase 2 (Gpd2), high-affinity glucose transporter 1 (Hgt1), and phosphoglycerate mutase (Gpm1) (35). The Gram positive bacterium S. aureus has two identified factor $\mathrm{H}$ ligands, serine-aspartate repeat protein $\mathrm{E}$ (SdrE) and Staphylococcus aureus binder of $\operatorname{IgG}$ (Sbi) (59, 60). For Streptococcus pneumoniae two factor $\mathrm{H}$ ligands, i.e., Tuf from also recruits plasma regulators and $\mathrm{PspC}$ are identified (16). Borrelia burgdorferi expresses five surface expressed complement regulators acquiring surface proteins, CRASP1-CRASP-5 and which confers Borrelia resistant to host complement attack $(61,62)$.

C. albicans expresses multiple plasminogen binding proteins, and over 12 plasminogen binding proteins are identified, i.e., pH-regulated antigen 1 (Pral) (35), phosphoglycerate mutase (Gpm1), glycerol-3-phosphate dehydrogenase 2 (Gpd2), transcription elongation factor (Tef1), enolase (Eno1) (42), alcohol dehydrogenase (Adh1), glyceraldehyde-3-phosphate dehydrogenase (Tdh3), thiol-specific antioxidant-like protein 1 (Tsa1), phosphoglycerate kinase (Pgk1), fructose bisphosphate (Fba1), catalase (Cta1), and aldolase $(35,63-65)$. Expression of several plasma regulator-binding proteins by pathogens can be extrapolated to A. fumigatus.

In conclusion, AfEnol from A. fumigatus is a moonlighting protein and allergen. AfEnol surface expression is developmentally regulated. AfEnol is expressed on the surface of swollen conidia and hyphae but not on resting conidia. Surface-exposed AfEno1 binds four human complement regulators which mediate/contribute to fungal survival in an immunocompetent host. AfEnol hijacks the human zymogen plasminogen and tPA; activated plasmin damages human lung epithelial cells and degrades EMC proteins, thereby allowing tissue penetration, colonization, and dissemination. Given these multifaceted features, AfEno1 may represent a therapeutic target to fight $A$. fumigatus infection.

\section{Statistical Analysis}

Statistical analyses of unpaired $t$-tests were performed with Prism 5 (GraphPad Inc., La Jolla, CA, USA). Differences with $P<0.05$ were considered significant, and significance between two groups is shown as ${ }^{*} P<0.05,{ }^{* *} P<0.01,{ }^{* *} P<0.001$.

\section{DATA AVAILABILITY STATEMENT}

All datasets generated for this study are included in the article/Supplementary Material.

\section{ETHICS STATEMENT}

The studies involving human participants were reviewed and approved by University Hospital Jena. The patients/participants provided their written informed consent to participate in this study.

\section{AUTHOR CONTRIBUTIONS}

$\mathrm{PD}, \mathrm{NB}, \mathrm{PZ}, \mathrm{CS}$, and $\mathrm{AB}$ designed and planned experiments. AS-R, MF, PZ, CS, and AB analyzed data. AS-R, PD, SD, $\mathrm{NK}$, IS, and DW performed experiments. SD, PD, AB, PZ, $\mathrm{CS}$, and MF evaluated data. PD, PZ, CS, MF, and NB wrote the manuscript.

\section{FUNDING}

The work was supported by the Collaborative Research Center/Transregio 124 FungiNet of the Deutsche Forschungsgemeinschaft (DFG) projects C6 (PZ, NB), C4 (CS), B4 (MF), and A1 (AB). AS-R was funded by a scholarship from PASPA-DGAPA National Autonomous University of Mexico (UNAM) and from Mexican National Science and Technology Council (CONACYT).

\section{SUPPLEMENTARY MATERIAL}

The Supplementary Material for this article can be found online at: https://www.frontiersin.org/articles/10.3389/fimmu. 2019.02573/full\#supplementary-material

Supplementary Figure 1 | Expression and purification of recombinant AfEno1 protein A. fumigatus AfEno1 was cloned, expressed in E. coli, and purified by Ni-NTA chromatography. (A) Proteins were separated by SDS-PAGE and visualized by Silver stain. S represents supernatant after IPTG induction (lane 1). $\mathrm{FT}$ is flow through after Ni-NTA column (lane 2), and W1 and W2 are washes (lane 4-5). E1 and E2 show elution fractions (lanes 6-8). The elution fractions were pooled and different amounts of protein was separated by SDS-PAGE, transferred to a membrane. Recombinant AfEno1 was identified by Western blotting with either (B) monoclonal anti-his antibody (lanes 1-2) or (C) AfEno1 antiserum (lanes $1-2)$.

Supplementary Figure 2 | Recombinant AfEno1 binds to plasma regulators. (A) AfEno1 binds to Factor $\mathrm{H}$ dose-dependently. Factor $\mathrm{H}$ was immobilized onto a microtiter plate, and AfEno1 at increasing amounts was added. After washing, bound AfEno1 was detected with rabbit AfEno1 antiserum. AfEno1 did not bind to gelatin. (B) AfEno1 binds to FHL-1 dose-dependently. AfEno1 at indicated amounts was added to immobilized FHL-1, and attached AfEno1 was detected 
with rabbit AfEno1 antiserum. FHL-1 showed no binding to gelatin. (C) Serum-derived Factor $\mathrm{H}$ binds to AfEno1 dose-dependently. NHS at increasing amounts was added to immobilized AfEno1. After washing, bound Factor $\mathrm{H}$ was detected with goat human Factor $\mathrm{H}$ antiserum. (D) C4BP binding to AfEno1 was

\section{REFERENCES}

1. Poltermann S, Kunert A, von der Heide M, Eck R, Hartmann A, Zipfel PF. Gpmlp is a factor H-, FHL-1-, and plasminogen-binding surface protein of Candida albicans. J Biol Chem. (2007) 282:37537-44. doi: 10.1074/jbc.M707280200

2. Taccone FS, Van den Abeele AM, Bulpa P, Misset B, Meersseman W, Cardoso $\mathrm{T}$, et al. Epidemiology of invasive aspergillosis in critically ill patients: clinical presentation, underlying conditions, and outcomes. Crit Care. (2015) 19:7. doi: 10.1186/s13054-014-0722-7

3. Agarwal V, Hammerschmidt S, Malm S, Bergmann S, Riesbeck K, Blom AM. Enolase of Streptococcus pneumoniae binds human complement inhibitor C4b-binding protein and contributes to complement evasion. J Immunol. (2012) 189:3575-84. doi: 10.4049/jimmunol.1102934

4. Agarwal R, Chakrabarti A, Shah A, Gupta D, Meis JF, Guleria R, et al. Allergic bronchopulmonary aspergillosis: review of literature and proposal of new diagnostic and classification criteria. Clin Exp Allergy. (2013) 43:850-73. doi: $10.1111 /$ cea.12141

5. Overton NLD, Brakhage AA, Thywissen A, Denning DW, Bowyer P. Mutations in EEA1 are associated with allergic bronchopulmonary aspergillosis and affect phagocytosis of Aspergillus fumigatus by human macrophages. PLoS ONE. (2018) 13:e0185706. doi: 10.1371/journal.pone.0185706

6. Dagenais TR, Keller NP. Pathogenesis of Aspergillus fumigatus in invasive Aspergillosis. Clin Microbiol Rev. (2009) 22:447-65. doi: 10.1128/CMR.00055-08

7. Chen J, Ryu S, Gharib SA, Goodlett DR, Schnapp LM. Exploration of the normal human bronchoalveolar lavage fluid proteome. Proteomics Clin Appl. (2008) 2:585-95. doi: 10.1002/prca.200780006

8. Bartlett JA, Albertolle ME, Wohlford-Lenane C, Pezzulo AA, Zabner J, Niles RK, et al. Protein composition of bronchoalveolar lavage fluid and airway surface liquid from newborn pigs. Am J Physiol Lung Cell Mol Physiol. (2013) 305:L256-66. doi: 10.1152/ajplung.00056.2013

9. Zipfel PF, Skerka C. Complement regulators and inhibitory proteins. Nat Rev Immunol. (2009) 9:729-40. doi: 10.1038/nri2620

10. Zipfel PF, Hallstrom T, Riesbeck K. Human complement control and complement evasion by pathogenic microbes-tipping the balance. Mol Immunol. (2013) 56:152-60. doi: 10.1016/j.molimm.2013.05.222

11. Zipfel PF, Skerka C. Staphylococcus aureus: the multi headed hydra resists and controls human complement response in multiple ways. Int J Med Microbiol. (2014) 304:188-94. doi: 10.1016/j.ijmm.2013.11.004

12. Ermert D, Blom AM. C4b-binding protein: the good, the bad and the deadly. Novel functions of an old friend. Immunol Lett. (2016) 169:82-92. doi: 10.1016/j.imlet.2015.11.014

13. Blom AM, Villoutreix BO, Dahlback B. Complement inhibitor C4b-binding protein-friend or foe in the innate immune system? Mol Immunol. (2004) 40:1333-46. doi: 10.1016/j.molimm.2003.12.002

14. Blom AM, Kask L, Dahlback B. CCP1-4 of the C4b-binding protein alphachain are required for factor I mediated cleavage of complement factor C3b. Mol Immunol. (2003) 39:547-56. doi: 10.1016/S0161-5890(02)00213-4

15. Barthel D, Schindler S, Zipfel PF. Plasminogen is a complement inhibitor. J Biol Chem. (2012) 287:18831-42. doi: 10.1074/jbc.M111.323287

16. Mohan S, Hertweck C, Dudda A, Hammerschmidt S, Skerka C, Hallstrom $\mathrm{T}$, et al. Tuf of Streptococcus pneumoniae is a surface displayed human complement regulator binding protein. Mol Immunol. (2014) 62:249-64. doi: 10.1016/j.molimm.2014.06.029

17. Sun H. The interaction between pathogens and the host coagulation system. Physiology. (2006) 21:281-8. doi: 10.1152/physiol.00059.2005

18. Keshari RS, Silasi R, Lupu C, Taylor FB Jr, Lupu F. In vivo-generated thrombin and plasmin do not activate the complement system in baboons. Blood. (2017) 130:2678-81. doi: 10.1182/blood-2017-06-788216 assayed by ELISA. AfEno1 was immobilized onto a microtiter plate overnight, and C4BP at increasing amounts was added. After washing, bound C4BP was detected with goat human C4BP antiserum. C4BP showed no binding to gelatin. (A-D) show mean values \pm SD from three separate experiments.

19. Meinel C, Sparta G, Dahse HM, Horhold F, Konig R, Westermann M, et al. Streptococcus pneumoniae from patients with hemolytic uremic syndrome binds human plasminogen via the surface protein PspC and uses plasmin to damage human endothelial cells. J Infect Dis. (2018) 217:358-70. doi: 10.1093/infdis/jix305

20. Kozel TR, Wilson MA, Farrell TP, Levitz SM. Activation of C3 and binding to Aspergillus fumigatus conidia and hyphae. Infect Immun. (1989) 57:3412-7.

21. Sturtevant JE, Latge JP. Interactions between conidia of Aspergillus fumigatus and human complement component C3. Infect Immun. (1992) 60:1913-8.

22. Speth C, Rambach G. Complement attack against Aspergillus and corresponding evasion mechanisms. Interdiscip Perspect Infect Dis. (2012) 2012:463794. doi: 10.1155/2012/463794

23. Behnsen J, Hartmann A, Schmaler J, Gehrke A, Brakhage AA, Zipfel PF. The opportunistic human pathogenic fungus Aspergillus fumigatus evades the host complement system. Infect Immun. (2008) 76:820-7. doi: 10.1128/IAI.01037-07

24. Moalli F, Doni A, Deban L, Zelante T, Zagarella S, Bottazzi B, et al. Role of complement and $\mathrm{Fc}$ \{gamma\} receptors in the protective activity of the long pentraxin PTX3 against Aspergillus fumigatus. Blood. (2010) 116:5170-80. doi: 10.1182/blood-2009-12-258376

25. Ma YJ, Doni A, Hummelshoj T, Honore C, Bastone A, Mantovani A, et al. Synergy between ficolin-2 and pentraxin 3 boosts innate immune recognition and complement deposition. J Biol Chem. (2009) 284:28263-75. doi: 10.1074/jbc.M109.009225

26. Vogl G, Lesiak L, Jensen DB, Perkhofer S, Eck R, Speth C, et al. Immune evasion by acquisition of complement inhibitors: the mould Aspergillus binds both factor $\mathrm{H}$ and $\mathrm{C} 4 \mathrm{~b}$ binding protein. Mol Immunol. (2008) 45:1485-93. doi: 10.1016/j.molimm.2007. 08.011

27. Behnsen J, Lessing F, Schindler S, Wartenberg D, Jacobsen ID, Thoen $\mathrm{M}$, et al. Secreted Aspergillus fumigatus protease Alp1 degrades human complement proteins C3, C4, and C5. Infect Immun. (2010) 78:3585-94. doi: 10.1128/IAI.01353-09

28. Shende R, Wong SSW, Rapole S, Beau R, Ibrahim-Granet O, Monod $\mathrm{M}$, et al. Aspergillus fumigatus conidial metalloprotease Meplp cleaves host complement proteins. J Biol Chem. (2018) 293:15538-55. doi: 10.1074/jbc.RA117.001476

29. Hector RF, Yee E, Collins MS. Use of $\mathrm{DBA} / 2 \mathrm{~N}$ mice in models of systemic candidiasis and pulmonary and systemic aspergillosis. Infect Immun. (1990) 58:1476-8

30. Heinekamp T, Schmidt H, Lapp K, Pahtz V, Shopova I, Koster-Eiserfunke N, et al. Interference of Aspergillus fumigatus with the immune response. Semin Immunopathol. (2015) 37:141-52. doi: 10.1007/s00281-014-0465-1

31. Crosdale DJ, Poulton KV, Ollier WE, Thomson W, Denning DW. Mannose-binding lectin gene polymorphisms as a susceptibility factor for chronic necrotizing pulmonary aspergillosis. J Infect Dis. (2001) 184:653-6. doi: $10.1086 / 322791$

32. He Q, Li H, Rui Y, Liu L, He B, Shi Y, et al. Pentraxin 3 gene polymorphisms and pulmonary aspergillosis in COPD patients. Clin Infect Dis. (2018) 66:2617. doi: $10.1093 / \mathrm{cid} / \mathrm{cix} 749$

33. Singh B, Sharma GL, Oellerich M, Kumar R, Singh S, Bhadoria DP, et al Novel cytosolic allergens of Aspergillus fumigatus identified from germinating conidia. J Proteome Res. (2010) 9:5530-41. doi: 10.1021/pr100605c

34. Dasari P, Shopova IA, Stroe M, Wartenberg D, Martin-Dahse H, Beyersdorf $\mathrm{N}$, et al. Aspf2 From Aspergillus fumigatus recruits human immune regulators for immune evasion and cell damage. Front Immunol. (2018) 9:1635. doi: 10.3389/fimmu.2018.01635

35. Luo S, Dasari P, Reiher N, Hartmann A, Jacksch S, Wende E, et al. The secreted Candida albicans protein Pra1 disrupts host defense by broadly targeting and blocking complement C3 and C3 activation fragments. Mol Immunol. (2018) 93:266-77. doi: 10.1016/j.molimm.2017.07.010 
36. Ito K, Ishiguro A, Kanbe T, Tanaka K, Torii S. Characterization of IgE-binding epitopes on Candida albicans enolase. Clin Exp Allergy. (1995) 25:529-35. doi: 10.1111/j.1365-2222.1995.tb01090.x

37. Bergmann S, Rohde M, Chhatwal GS, Hammerschmidt S. alphaEnolase of Streptococcus pneumoniae is a plasmin(ogen)-binding protein displayed on the bacterial cell surface. Mol Microbiol. (2001) 40:1273-87. doi: 10.1046/j.1365-2958.2001.02448.x

38. Jong AY, Chen SH, Stins MF, Kim KS, Tuan TL, Huang SH. Binding of Candida albicans enolase to plasmin(ogen) results in enhanced invasion of human brain microvascular endothelial cells. J Med Microbiol. (2003) 52(Pt 8):615-22. doi: 10.1099/jmm.0.05060-0

39. Nogueira SV, Fonseca FL, Rodrigues ML, Mundodi V, Abi-Chacra EA, Winters MS, et al. Paracoccidioides brasiliensis enolase is a surface protein that binds plasminogen and mediates interaction of yeast forms with host cells. Infect Immun. (2010) 78:4040-50. doi: 10.1128/IAI.00221-10

40. Ghosh AK, Coppens I, Gardsvoll H, Ploug M, Jacobs-Lorena M. Plasmodium ookinetes coopt mammalian plasminogen to invade the mosquito midgut. Proc Natl Acad Sci USA. (2011) 108:17153-8. doi: 10.1073/pnas.1103657108

41. Nogueira SV, Smith AA, Qin JH, Pal U. A surface enolase participates in Borrelia burgdorferi-plasminogen interaction and contributes to pathogen survival within feeding ticks. Infect Immun. (2012) 80:82-90. doi: 10.1128/IAI.05671-11

42. Funk J, Schaarschmidt B, Slesiona S, Hallstrom T, Horn U, Brock M. The glycolytic enzyme enolase represents a plasminogen-binding protein on the surface of a wide variety of medically important fungal species. Int J Med Microbiol. (2016) 306:59-68. doi: 10.1016/j.ijmm.2015.11.005

43. Salazar N, Souza MC, Biasioli AG, Silva LB, Barbosa AS. The multifaceted roles of Leptospira enolase. Res Microbiol. (2017) 168:157-64. doi: 10.1016/j.resmic.2016.10.005

44. Weidner G, d'Enfert C, Koch A, Mol PC, Brakhage AA. Development of a homologous transformation system for the human pathogenic fungus Aspergillus fumigatus based on the pyrG gene encoding orotidine 5'-monophosphate decarboxylase. Curr Genet. (1998) 33:378-85. doi: $10.1007 /$ s002940050350

45. Kuhn S, Skerka C, Zipfel PF. Mapping of the complement regulatory domains in the human factor H-like protein 1 and in factor H1. J Immunol. (1995) 155:5663-70.

46. Bergfeld A, Dasari P, Werner S, Hughes TR, Song WC, Hortschansky P, et al. Direct binding of the $\mathrm{pH}$-regulated Protein 1 (Pra1) from Candida albicans inhibits cytokine secretion by mouse CD4(+) T cells. Front Microbiol. (2017) 8:844. doi: 10.3389/fmicb.2017.00844

47. Bacher P, Kniemeyer O, Teutschbein J, Thon M, Vodisch M, Wartenberg $\mathrm{D}$, et al. Identification of immunogenic antigens from Aspergillus fumigatus by direct multiparameter characterization of specific conventional and regulatory $\mathrm{CD}^{+} \mathrm{T}$ cells. J Immunol. (2014) 193:3332-43. doi: 10.4049/jimmunol.1400776

48. Meri T, Amdahl H, Lehtinen MJ, Hyvarinen S, McDowell JV, Bhattacharjee A, et al. Microbes bind complement inhibitor factor $\mathrm{H}$ via a common site. PLoS Pathog. (2013) 9:e1003308. doi: 10.1371/journal.ppat.1003308

49. Weismann D, Hartvigsen K, Lauer N, Bennett KL, Scholl HP, Charbel Issa $\mathrm{P}$, et al. Complement factor $\mathrm{H}$ binds malondialdehyde epitopes and protects from oxidative stress. Nature. (2011) 478:76-81. doi: 10.1038/nature10449

50. Brissette CA, Haupt K, Barthel D, Cooley AE, Bowman A, Skerka C, et al. Borrelia burgdorferi infection-associated surface proteins ErpP, ErpA, and ErpC bind human plasminogen. Infect Immun. (2009) 77:300-6. doi: 10.1128/IAI.01133-08

51. Eroles P, Sentandreu M, Elorza MV, Sentandreu R. Cloning of a DNA fragment encoding part of a $70-\mathrm{kDa}$ heat shock protein of Candida albicans. FEMS Microbiol Lett. (1995) 128:95-100. doi: 10.1111/j.1574-6968.1995.tb07506.x

52. Fox D, Smulian AG. Plasminogen-binding activity of enolase in the opportunistic pathogen Pneumocystis carinii. Med Mycol. (2001) 39:495-507. doi: $10.1080 / 714031070$

53. Chaudhary N, Staab JF, Marr KA. Healthy human T-cell responses to Aspergillus fumigatus antigens. PLoS ONE. (2010) 5:e9036. doi: 10.1371/journal.pone.0009036
54. Jeffery CJ. An introduction to protein moonlighting. Biochem Soc Trans. (2014) 42:1679-83. doi: 10.1042/BST20140226

55. Gil-Bona A, Llama-Palacios A, Parra CM, Vivanco F, Nombela C, Monteoliva $\mathrm{L}$, et al. Proteomics unravels extracellular vesicles as carriers of classical cytoplasmic proteins in Candida albicans. J Proteome Res. (2015) 14:142-53. doi: $10.1021 / \operatorname{pr} 5007944$

56. Wattiez R, Falmagne P. Proteomics of bronchoalveolar lavage fluid. J Chromatogr B Analyt Technol Biomed Life Sci. (2005) 815:169-78. doi: 10.1016/j.jchromb.2004.10.029

57. Banerjee B, Greenberger PA, Fink JN, Kurup VP. Immunological characterization of Asp f 2, a major allergen from Aspergillus fumigatus associated with allergic bronchopulmonary aspergillosis. Infect Immun. (1998) 66:5175-82.

58. Knutsen AP, Hutcheson PS, Slavin RG, Kurup VP. IgE antibody to Aspergillus fumigatus recombinant allergens in cystic fibrosis patients with allergic bronchopulmonary aspergillosis. Allergy. (2004) 59:198-203. doi: 10.1046/j.1398-9995.2003.00310.x

59. Haupt K, Reuter M, van den Elsen J, Burman J, Halbich S, Richter J, et al. The Staphylococcus aureus protein Sbi acts as a complement inhibitor and forms a tripartite complex with host complement Factor $\mathrm{H}$ and C3b. PLoS Pathog. (2008) 4:e1000250. doi: 10.1371/journal.ppat.10 00250

60. Zhang Y, Wu M, Hang T, Wang C, Yang Y, Pan W, et al. Staphylococcus aureus SdrE captures complement factor H's C-terminus via a novel 'close, dock, lock and latch' mechanism for complement evasion. Biochem J. (2017) 474:1619-31. doi: 10.1042/BCJ201 70085

61. Kraiczy P, Hellwage J, Skerka C, Becker H, Kirschfink M, Simon MM, et al. Complement resistance of Borrelia burgdorferi correlates with the expression of BbCRASP-1, a novel linear plasmid-encoded surface protein that interacts with human factor $\mathrm{H}$ and FHL-1 and is unrelated to Erp proteins. J Biol Chem. (2004) 279:2421-9. doi: 10.1074/jbc.M3083 43200

62. von Lackum K, Miller JC, Bykowski T, Riley SP, Woodman ME, Brade V, et al. Borrelia burgdorferi regulates expression of complement regulator-acquiring surface protein 1 during the mammal-tick infection cycle. Infect Immun. (2005) 73:7398-405. doi: 10.1128/IAI.73.11.7398-74 05.2005

63. Crowe JD, Sievwright IK, Auld GC, Moore NR, Gow NA, Booth NA. Candida albicans binds human plasminogen: identification of eight plasminogen-binding proteins. Mol Microbiol. (2003) 47:1637-51. doi: 10.1046/j.1365-2958.2003.03390.x

64. Luo S, Hoffmann R, Skerka C, Zipfel PF. Glycerol-3-phosphate dehydrogenase 2 is a novel factor $\mathrm{H}$-, factor $\mathrm{H}$-like protein 1-, and plasminogen-binding surface protein of Candida albicans. J Infect Dis. (2013) 207:594-603. doi: 10.1093/infdis/jis718

65. Luo S, Skerka C, Kurzai O, Zipfel PF. Complement and innate immune evasion strategies of the human pathogenic fungus Candida albicans. Mol Immunol. (2013) 56:161-9. doi: 10.1016/j.molimm.2013. 05.218

Conflict of Interest: The authors declare that the research was conducted in the absence of any commercial or financial relationships that could be construed as a potential conflict of interest.

The handling editor declared a past co-authorship with one of the authors PZ.

Copyright (C) 2019 Dasari, Koleci, Shopova, Wartenberg, Beyersdorf, Dietrich, Sahagún-Ruiz, Figge, Skerka, Brakhage and Zipfel. This is an open-access article distributed under the terms of the Creative Commons Attribution License (CC BY). The use, distribution or reproduction in other forums is permitted, provided the original author(s) and the copyright owner(s) are credited and that the original publication in this journal is cited, in accordance with accepted academic practice. No use, distribution or reproduction is permitted which does not comply with these terms. 